\title{
The Design-Build Process for the Research Support Facility
}
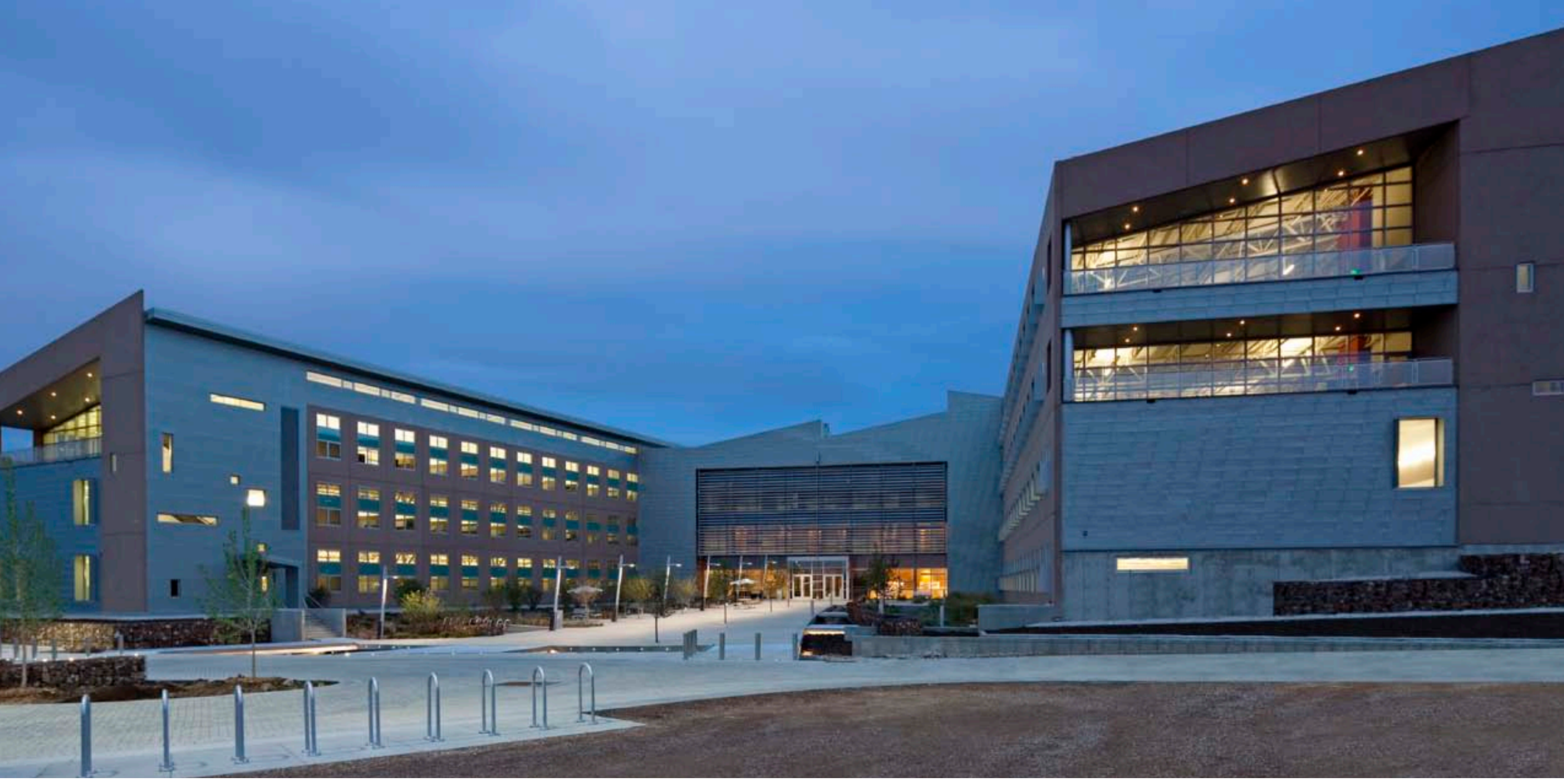

An in-depth look at how the U.S. Department of Energy and the National Renewable Energy Laboratory used a performance-based design-build contract process to build one of the most energy efficient office buildings in the world.

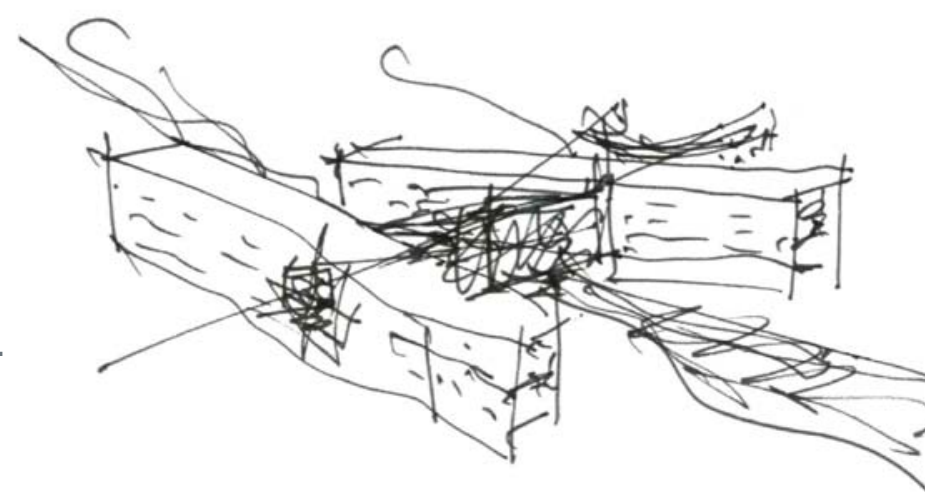





\section{Table of Contents}

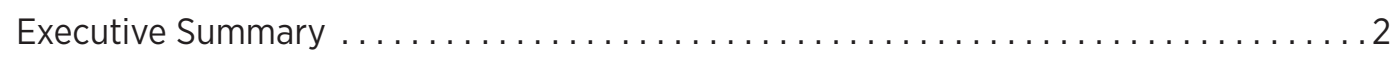

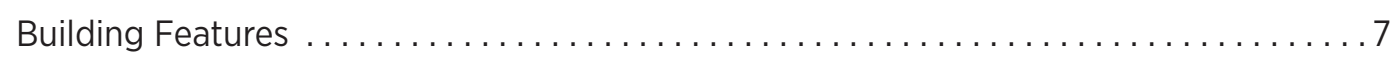

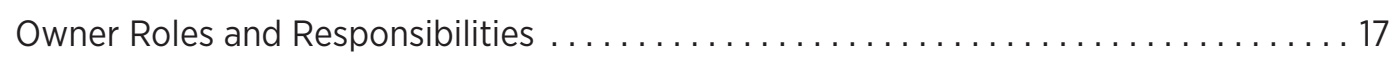

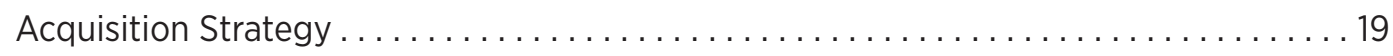

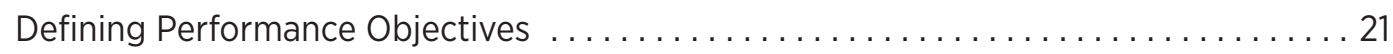

Acquisition Planning . . . . . . . . . . . . . . . . . . . . . . .

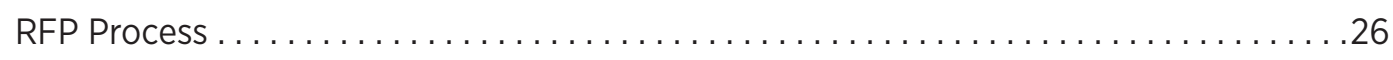

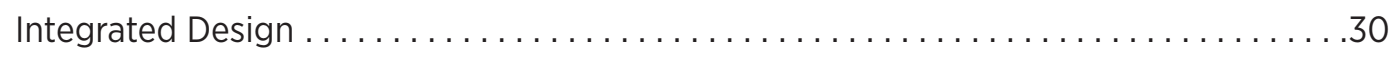

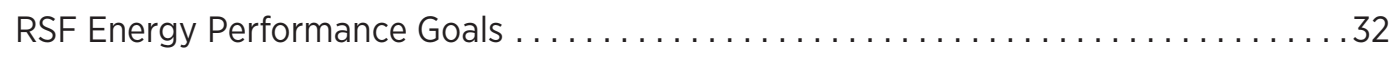

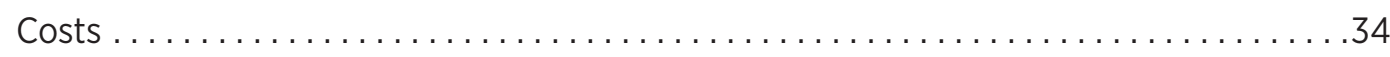

Why Performance-Based Design-Build Works. . . . . . . . . . . . . . . . 35

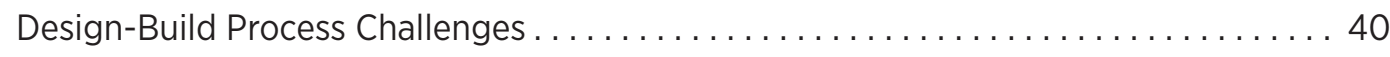

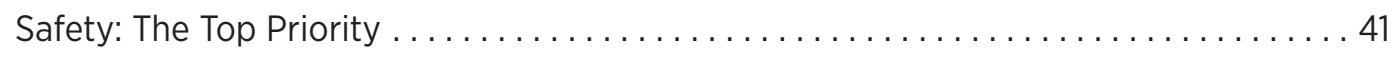

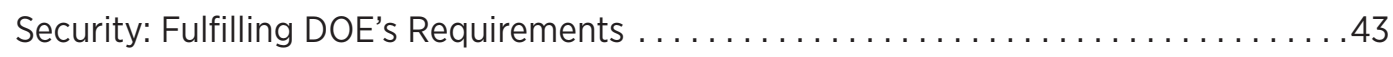

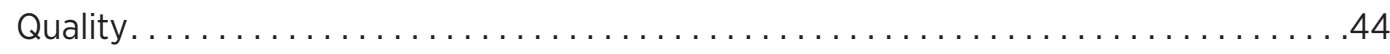

Using Photovoltaics and a Power Purchase Agreement. . . . . . . . . . . . . 45

Getting Employees Ready to Move to the "Workplace of the Future". . . . . . . . . 48

RSF Building Systems Performance To Date $\ldots \ldots \ldots \ldots \ldots \ldots \ldots \ldots \ldots \ldots \ldots \ldots \ldots \ldots \ldots \ldots \ldots \ldots$

Top "Must Haves" for a Successful Design-Build Project . . . . . . . . . . . . . . 54

Top 10 Tips for Design-Build Projects $\ldots \ldots \ldots \ldots \ldots \ldots \ldots \ldots \ldots \ldots \ldots \ldots \ldots \ldots \ldots \ldots \ldots \ldots \ldots \ldots \ldots \ldots \ldots$

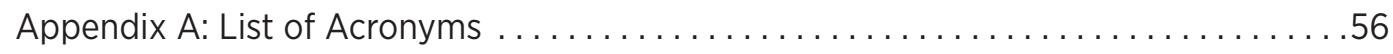

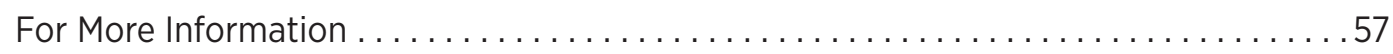




\section{Executive Summary}

The Research Support Facility (RSF) project is an opportunity for the U.S. Department of Energy's (DOE) Office of Energy Efficiency and Renewable Energy (EERE) to directly impact national energy security by redefining the standard for commercial buildings.

The RSF, which is located on the main campus of the National Renewable Energy Laboratory (NREL) in Golden, Colorado, was completed in June 2010. It is a showcase for sustainable, high-performance design that incorporates the best in energy efficiency, environmental performance, and advanced controls using a "whole building" integrated design process.

The building serves as a model for cost-competitive, high energy performance commercial buildings for the nation's design, construction, operation, and financing communities. The RSF is also a living laboratory for EERE's buildings technologies, providing real-time data that allows researchers to discover opportunities for improved performance.

\section{Building Features}

RSF's superior energy performance was driven by a focus on energy efficiency in an integrated whole building design strategy. Once the building achieved its efficiency goals, renewable energy was added to achieve net zero energy. Energy efficient design can be done by anyone today. Energy efficiency features include:

- Building siting, orientation form, and massing driven by energy and environment

- Low energy consumption

- Daylighting

- Energy efficient lighting

- Natural ventilation

- Night purging

- Transpired solar collector

- Thermal basement labyrinth

- Radiant slabs

- Evaporative cooling

- Heat recovery from data center

- Renewable energy generated via photovoltaics on rooftop and parking

\section{Materials}

Materials used in the RSF contain recycled content, rapidly renewable products, or were regional, meaning they were procured within a 500-mile radius of Golden. Examples include: wood from pine trees killed by beetles used for the lobby entry; recycled runway materials from Denver's closed Stapleton Airport used for aggregate in foundations and slabs; and reclaimed steel natural gas piping used as structural columns. About $75 \%$ of construction waste materials have been diverted from landfills.

\section{Design-Build Approach}

To meet stringent time and performance goals - while mitigating costs and risks - the RSF project team developed an innovative performance-based designbuild approach that relied on integrated design and construction, extensive up-front planning, a national design competition, energy modeling, and a firm fixed-price contract. DOE and NREL invited nearly a dozen design-build teams to submit proposals. The design-build team of Haselden Construction and the architectural firm RNL won the design-build competition and began work in July 2008.

\section{"This building demonstrates that the energy performance of commercial buildings can be substantially improved using an integrated design process. Through this innovative approach-combined} with a relentless focus on the energy model-our team has created a new national building performance standard for large-scale commercial buildings that is achievable and marketable now."

- Jeff Baker, Director of Laboratory Operations, DOE's Office of Energy Efficiency and Renewable Energy 


\section{Workplace of the Future}

The RSF provides employees with a new type of office space - one that is open and encourages collaboration. Low profile, modular workstations allow daylight and views for all occupants. Workstations are located within 30 feet of the nearest window, and employees are able to open windows when conditions permit, allowing natural ventilation and improved indoor air quality.

\section{Achieving LEED ${ }^{\circledR}$ Platinum}

In June 2011, the RSF received the U.S. Green Building Council's Leadership in Energy and Environmental Design (LEED) Platinum standard - the highest thirdparty certification building standard currently defined.

\section{Changing the Way Buildings Are Built}

Buildings have a significant impact on energy use and the environment. Commercial and residential buildings use almost $41 \%$ of the primary energy and approximately $70 \%$ of the electricity in the United States.

The energy used by the building sector continues to increase, primarily because new buildings are constructed faster than old ones are retired. Electricity consumption in the commercial building sector doubled between 1980 and 2000 and is expected to increase another $50 \%$ by 2025 (Source: EIA).

With $19 \%$ of the primary energy in the United States consumed by commercial buildings, DOE's goal for the RSF project is to help change the way commercial buildings are designed and built.

The DOE Office of Energy Efficiency and Renewable Energy's Building Technologies Program works with the commercial building industry to develop and deploy effective technologies and tools to significantly reduce energy use in existing and new commercial buildings. By developing, demonstrating, and deploying costeffective solutions, this Program strives to reduce energy consumption across the commercial building sector by at least $50 \%$ by 2030 .

NREL's building researchers are developing strategies and techniques to reduce energy use in commercial buildings, including those incorporated in the design of the RSF. NREL researchers are monitoring and documenting the energy performance of the RSF and sharing those results with industry to show how achievable ultra-energy efficient buildings are today.
FIGURE 1 Building Sector Energy Use

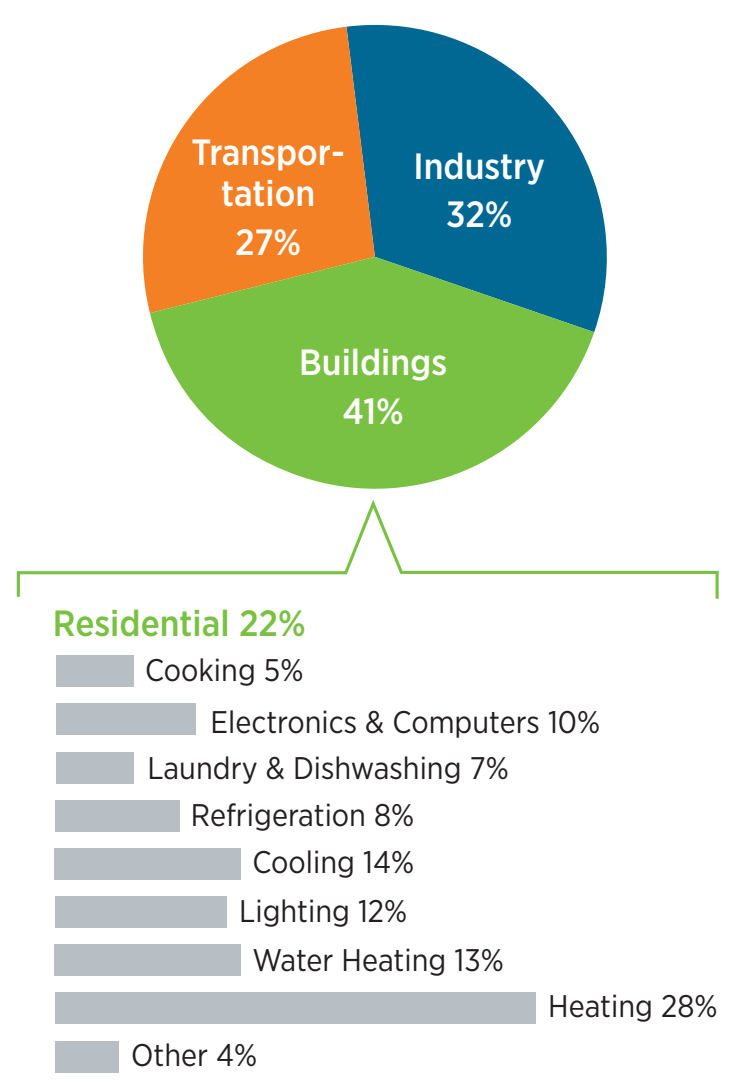

\section{Commercial 19\%}

Cooking $2 \%$

Refrigeration $4 \%$

Electronics \& Computers $12 \%$

Ventilation $7 \%$

Water Heating 7\%

Cooling $14 \%$

Heating $13 \%$

Lighting $27 \%$

Other $14 \%$

According to DOE's Buildings Energy Data Book, the commercial buildings sector uses $19 \%$ of energy in the U.S. Lighting accounts for $27 \%$ of energy use in commercial buildings. Figure by Stacy Buchanan, NREL 


\section{Facts at a Glance}

Headquarters Program: U.S. Department of Energy - Office of Energy Efficiency \& Renewable Energy (EERE)

Field Office: U.S. Department of Energy - Golden Field Office (GO)

Location: National Renewable Energy Laboratory (NREL) in Golden, Colorado

M\&O Contractor: Alliance for Sustainable Energy, LLC

NREL Managing Office: Infrastructure and Campus Development

Owner: U.S. DOE and NREL

\section{Design-Build Team:}

General Contractor - Haselden Construction

Architect - RNL

Sustainability Consultant and Mechanical, Electrical Engineer - Stantec

Design-Build RFP Consultant: DesignSense, Incorporated

Design-Build Owner's Representative: Northstar Project Management, Incorporated

Project Cost: $\$ 80$ million Total Project Cost

- \$64 million for design/construction and interiors

( $\$ 57.3$ million for construction only)

Contract Type: Performance-based design-build; firm fixed price

Size: $222,000 \mathrm{ft}^{2}$

Occupancy: Approximately 825 employees

Energy Goal: 35.1 kBtu/ft²/year (including data center)

Energy Performance: 50 percent better than ASHRAE 90.1, 2004 Standard

\section{"This building represents a turning point in American architecture and} construction. It's something like the creation of the Model T; it's not only a brilliant manufacturing concept, it's the ability to replicate it. The RSF represents an ability to replicate deep sustainability in practically any climate." 


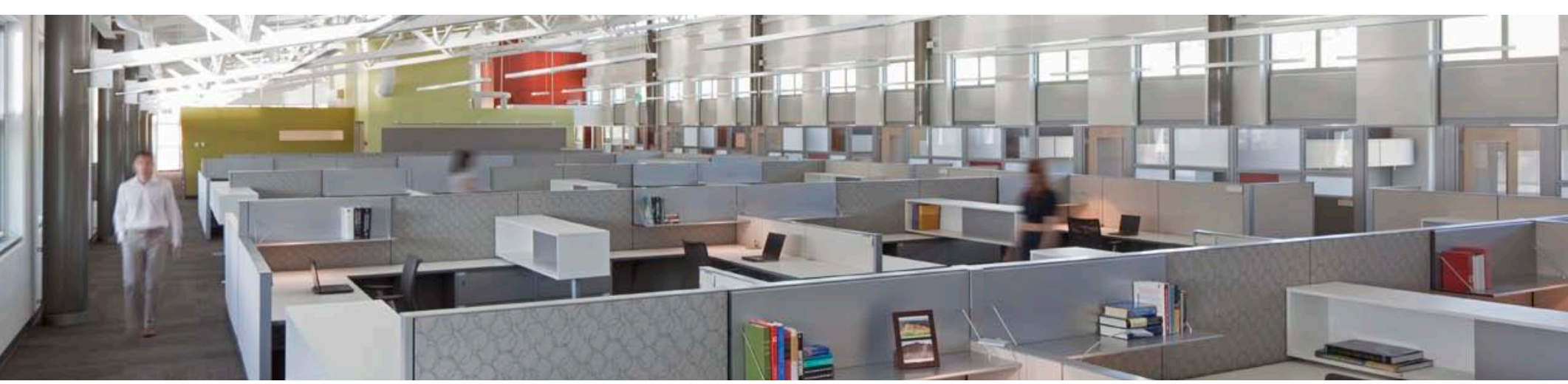

\section{The Need for the RSF}

Since the National Renewable Energy Laboratory (NREL) was initially formed in 1977 as the Solar Energy Research Institute, both the U.S. Department of Energy's (DOE) Golden Field Office (GO) and NREL have occupied leased office space in the Denver West Office complex across the highway from NREL's primary research facilities. While the distance is fairly close - just several miles - having the majority of NREL's research staff separate from its administrative staff posed several challenges.

First, workers must drive or take a shuttle to attend meetings or collaborate on projects on either side of the highway, which requires more time and lowers productivity. Second, leasing office space for more than 30 years imposed an additional strain on budgets. DOE's Office of Energy Efficiency and Renewable Energy (EERE) has paid more than $\$ 150$ million in leases to provide space for its NREL and DOE-GO employees. Lack of control over the leased space means more staff time spent negotiating needs. Finally, NREL and DOE-GO were not able to fully "walk the talk" when it came to energy efficiency and sustainability in the workplace, despite measures to encourage reduced energy use, recycling, and the use of fewer personal vehicles to drive around the campus.

For many years, NREL and DOE-GO looked at the possibility of developing federally-owned office space on NREL's South Table Mountain (STM) permanent site. Despite ongoing efforts at securing capital funding for this office space, DOE was not successful until late 2004 when EERE approved the Mission Need Statement for the RSF. DOE-GO received initial funding of \$9.9 million for the RSF in February 2006.

This marked the beginning of a multi-stage process to build one of the most energy efficient office buildings in the world.
The RSF features open work stations and a narrow building width that allows for maximum daylighting. Photo from Frank Ooms Photography

\section{"This is the way we need to be building buildings." \\ - Greg Collette, DOE Federal Project Manager}




\section{Project Timeline}

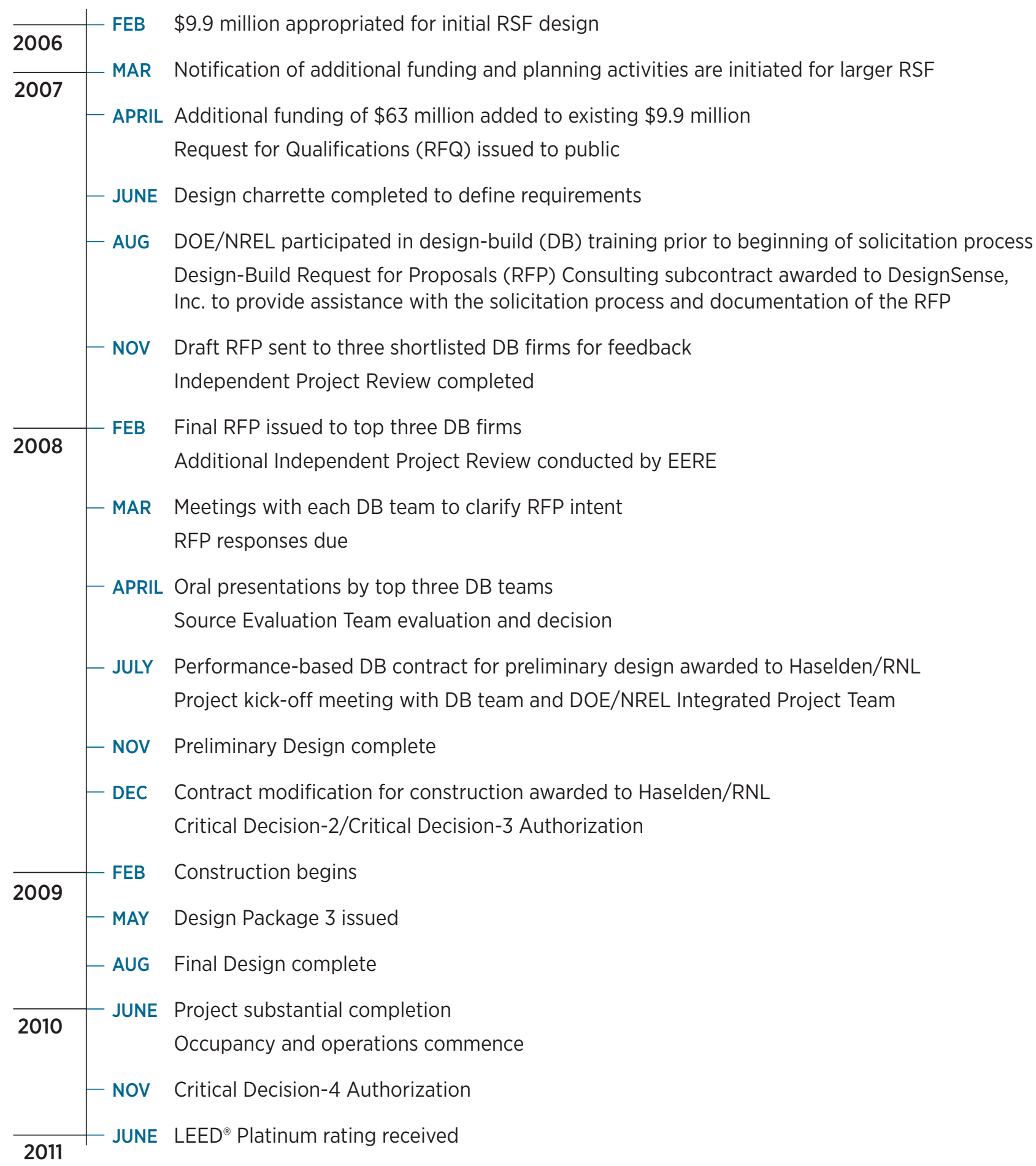




\section{Building Features}

From its early inception, the RSF was destined to be a world-changing building. With the goal of creating the largest commercial net-zero energy building in the country, the building is meant to serve as a blueprint for a net-zero energy future and influence others in the building industry to pursue ultra-energy efficiency and net-zero energy performance.

The design maximizes passive architectural strategies that take advantage of the climate and drive energy use reduction. The site orientation, plan, section, massing, and the envelope design all work to daylight and naturally ventilate the building. The architecture preheats its own ventilation air, and its exposed thermal mass and basement thermal labyrinth allow the building to store its own thermal energy. The architecture dramatically reduces the energy use first; then an extremely efficient lighting system, a radiant cooling and heating system,

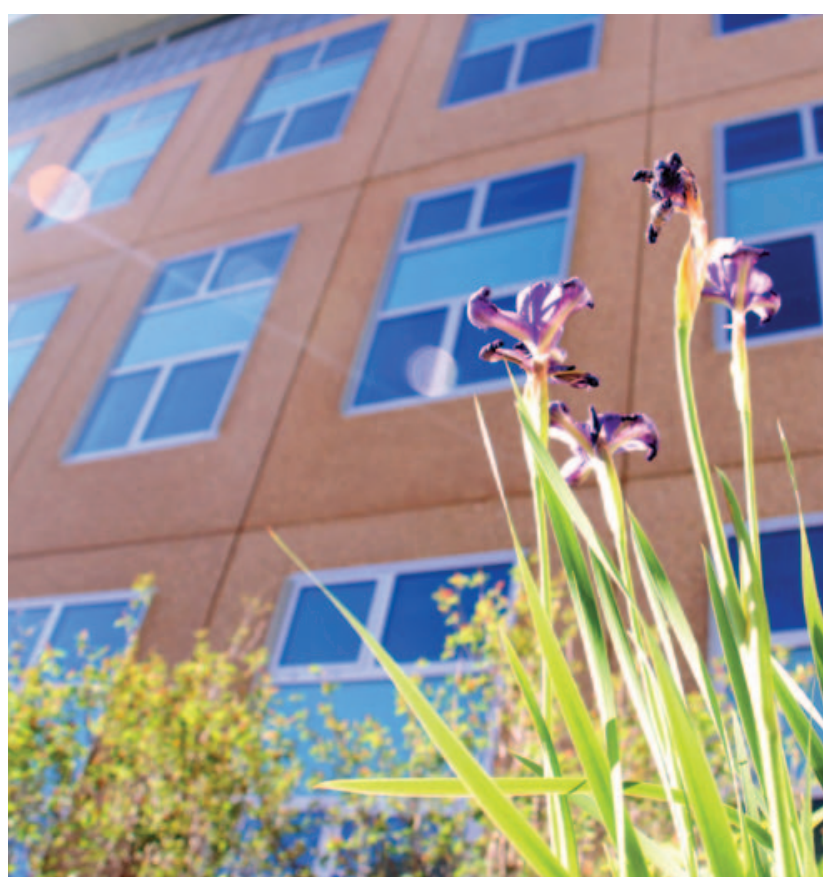

The RSF serves as a blueprint for achieving ultra-energy efficiency and net-zero energy performance. Photo by Heather Lammers, NREL/PIX 17515 and an underfloor air ventilation system further improve the energy performance of the building. The roof of the building tilts gently to the south to enhance energy generation from a roof-mounted photovoltaic system.

The workplace design not only supports the building's energy goals by facilitating proper daylighting, but natural ventilation and thermal mass exposure are designed to create the workplace of the future. With modular workstations, raised floor systems, and demountable walls, the interior environment is incredibly flexible and adaptable. The workplace promotes collaboration and accessibility across the hierarchy of the organization. Productivity and well-being are enhanced through indoor environmental quality features such as daylighting, thermal comfort and control, acoustical control, and improved air quality.

\section{Energy Efficiency and Renewable Energy}

The preliminary design goal was to make the RSF as energy efficient as possible. To achieve this efficiency, the design team determined that daylighting must play a big role. Once decided, the need for mechanical cooling was eliminated. Achieving net-zero energy requires optimization and integration of all the energy flows and systems of the building. Lighting is an integrated system of daylighting, daylight control systems, occupancy controls, and high efficiency lighting. Thermal comfort is addressed using an integrated system of thermal mass, radiant slabs, night purging, and natural ventilation. Heating has a whole systems approach to energy conservation.

The building includes a large thermal labyrinth under the two main office wings. The labyrinth can store heat from the transpired solar collectors on the south facades of the building. This heat is used to passively temper the ventilation air during the heating season. The labyrinth also serves as a thermal sink for rejected heat from the building's data center; dramatically lowering the cooling load of the data center year-round.

The building's extremely detailed energy model predicts an energy use intensity of $33 \mathrm{kBtu} / \mathrm{ft}^{2} / \mathrm{year}$. The on-site photovoltaic system is sized to meet net-zero site energy at an energy use intensity of $35 \mathrm{kBtu} / \mathrm{ft}^{2} /$ year.

\section{"What we've put together is more than a building. I firmly believe we're creating the future of our industry with the RSF project. We're not only making history, we're building it."




\section{Building and Energy Diagram}

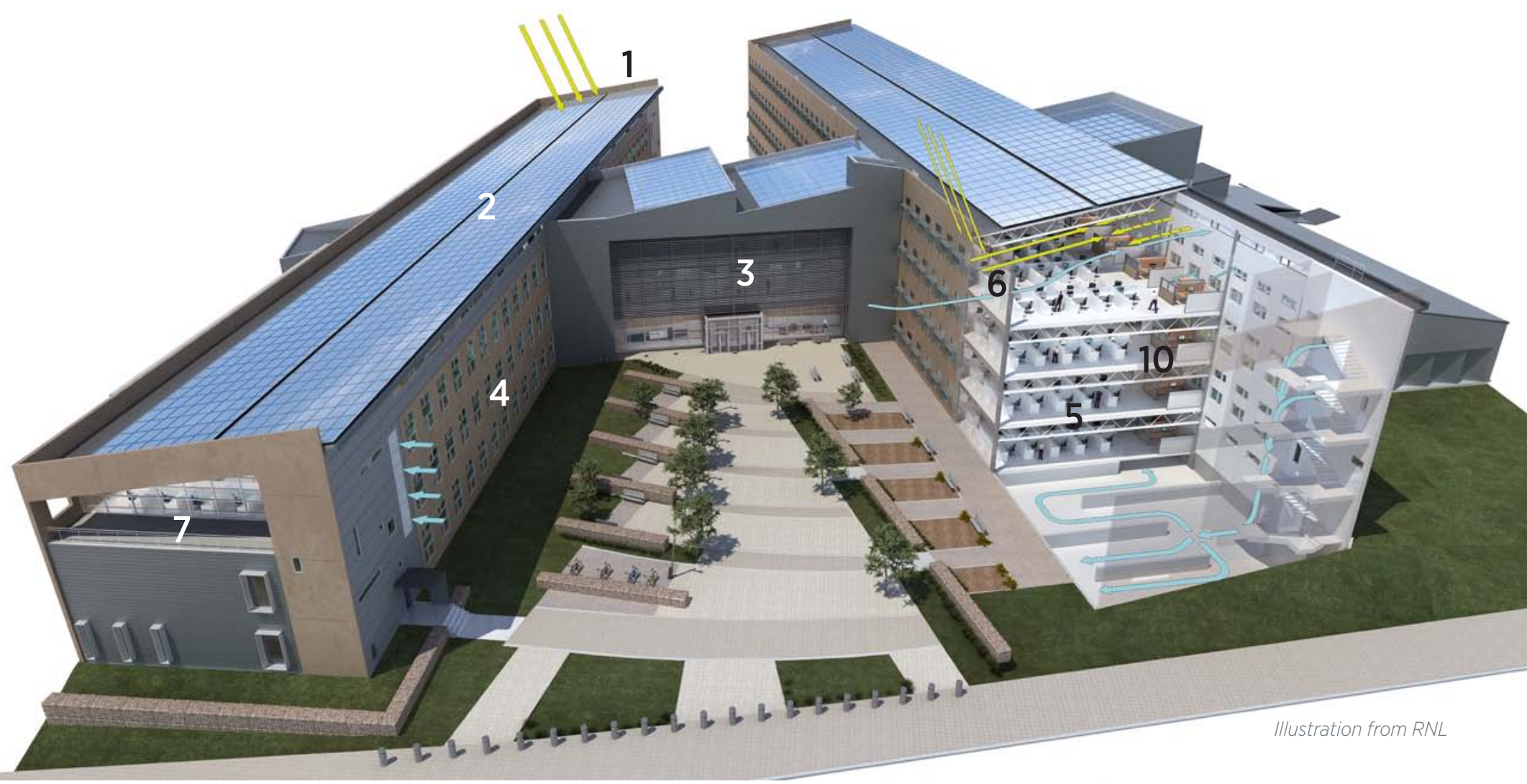

1 Building is organized in long $60 \mathrm{ft}$ wide office wings for optimal solar orientation

$21.6 \mathrm{MW}$ of photovoltaics on site; $450 \mathrm{~kW}$ on rooftop

3 Louvered sunshade protects glazing at the entrance lobby

4 Window to wall ratio for north and south walls is $25 \%$ and the windows are organized into daylighting and view sections

5 Radiant slabs provide heating and cooling from the exposed structure above

6 Manually operable windows allow for natural ventilation and automated operable windows can open during summer nights to night purge the spaces with cool air 


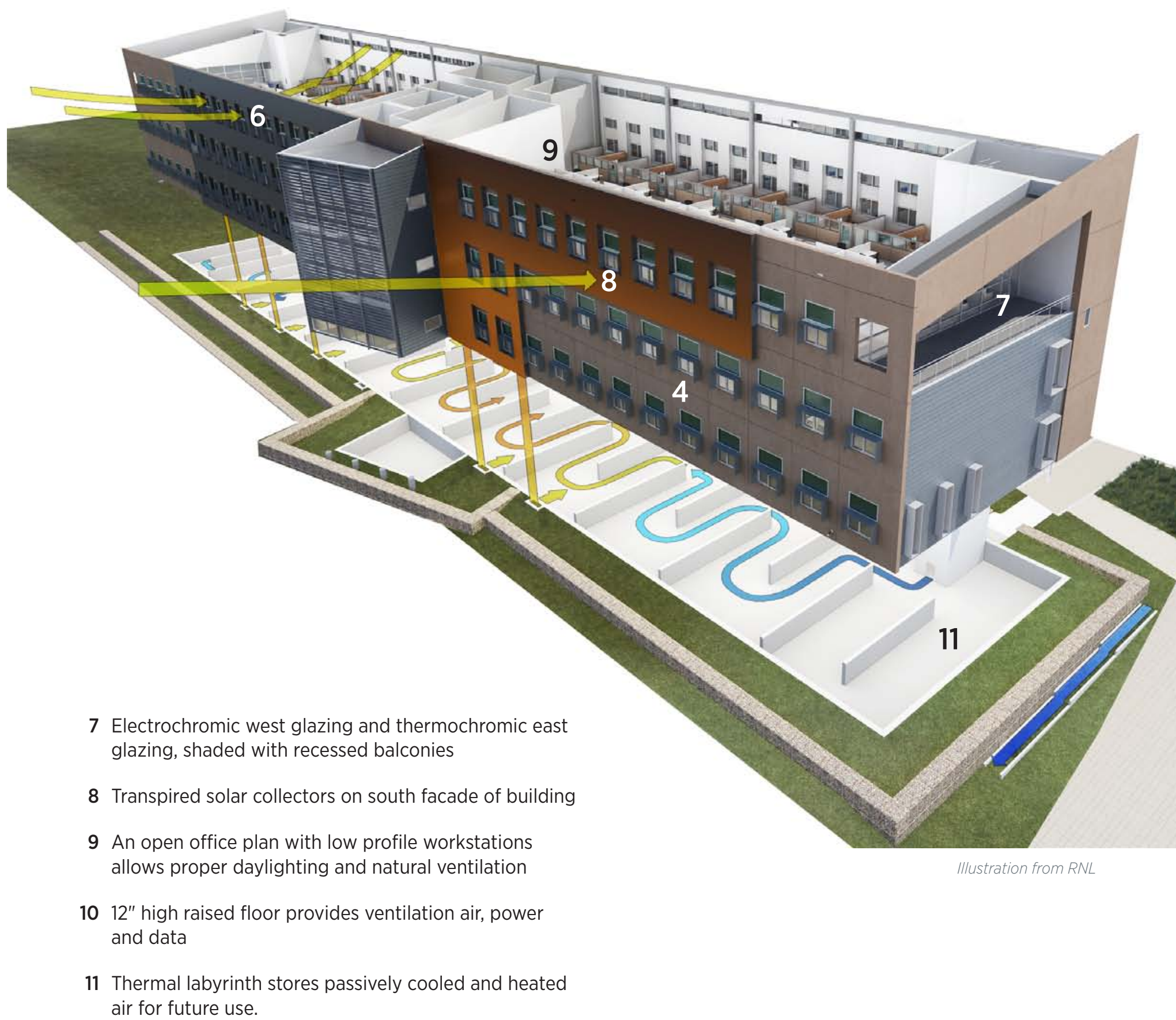




\section{Passive Heating and Cooling}

The RSF incorporates many passive heating and cooling techniques:

- Six inches of concrete on the interior of the precast exterior/interior insulated panels provides thermal mass that helps moderate internal temperatures year round.

- The labyrinth under the building also stores heat and cool air to help condition the building.

- Operable and automatic window controls allow natural ventilation and support nighttime cooling.

\section{Labyrinth Thermal Storage}

The lower floor of the RSF had to be built above grade since the soil beneath the building had to be removed because of expansive clay at the site. This created a large crawl space under the two long wings of the RSF, and the design team decided to place a labyrinth of staggered concrete walls, adding significant thermal mass.

During cold weather, air heated by the transpired solar collector heats the thermal mass, which then preheats ventilation air. The labyrinth can warm outside air by $5-10^{\circ} \mathrm{F}$.

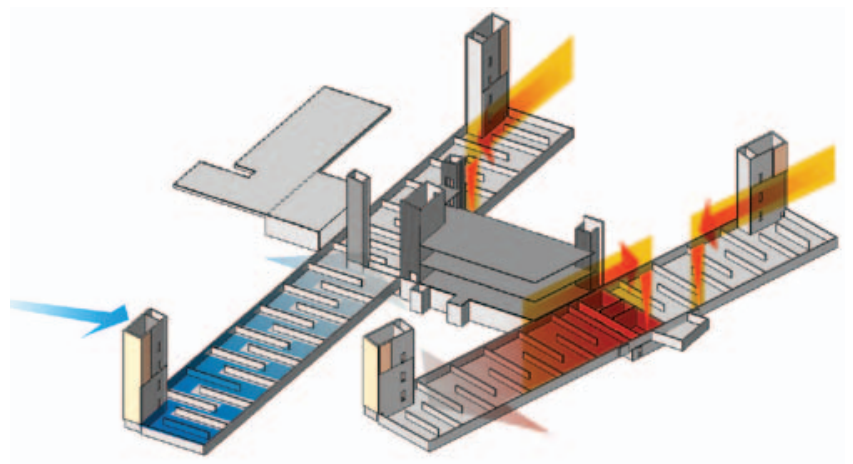

The RSF's basement labyrinth acts as a thermal battery. Illustration from RNL

\section{Transpired Solar Collector}

The transpired solar collector is a metal sheet perforated with small holes. Fans pull air through the holes on sunny winter days to preheat building ventilation air and "charge" the labyrinth. DOE/NREL and Conserval Engineering, Inc., jointly developed this simple, elegant unglazed collector, and won both the Popular Science Best of What's New Award and an R\&D Magazine R\&D 100 Award in 1994.

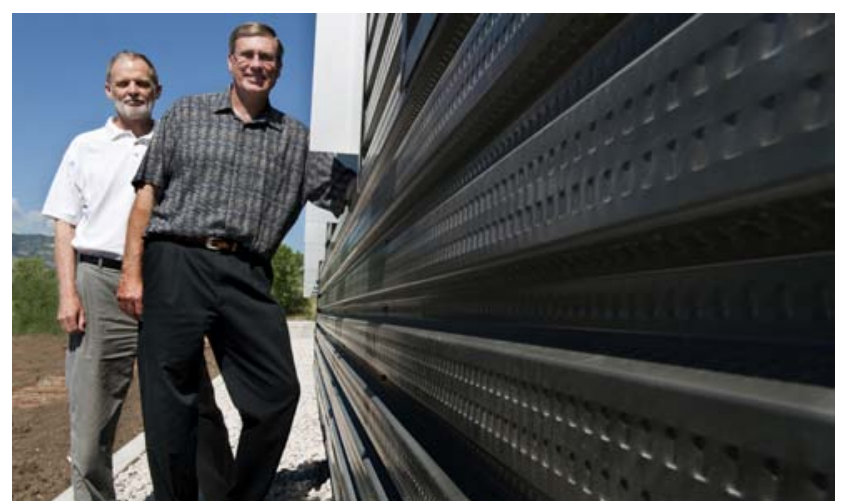

NREL researchers next to their award-winning transpired solar collector on the RSF's south wing. Photo by Dennis schroeder, NREL/PIX 17659

Sun heats up dark metal panel

Cold air is drawn into the collector through small perforations

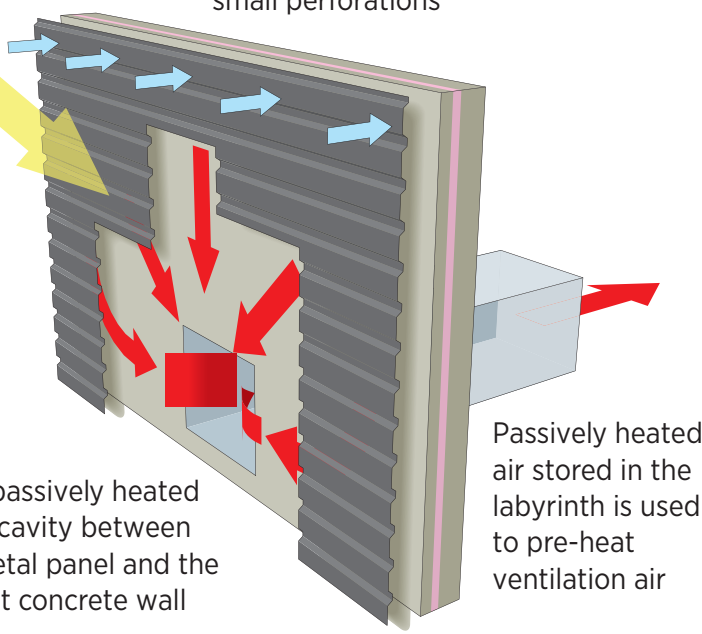

Diagram showing how the transpired solar collector works. Illustration from RNL 


\section{Precast Exterior/Interior Insulated Panels}

Because of the extensive exterior envelope required to optimize daylighting and natural ventilation, the DB team devised an exterior wall system that is modular, thermally massive, and carried on an efficient structural bay. The column-free structural grid is 30 feet by 60 feet, and integrates the building's "kit of parts" approach.

The precast panels that make up the exterior walls of the RSF consist of two inches of rigid insulation (R-14) sandwiched between three inches of architectural precast concrete on the outside and six inches of concrete on the inside. The panels, which were fabricated in Denver using concrete and aggregate from Colorado sources, constitute the finished surface on both the inside and outside of the wall except that the interior is primed and painted. Although the panels come in various sizes and shapes, they average 14.5 feet by 30 feet.

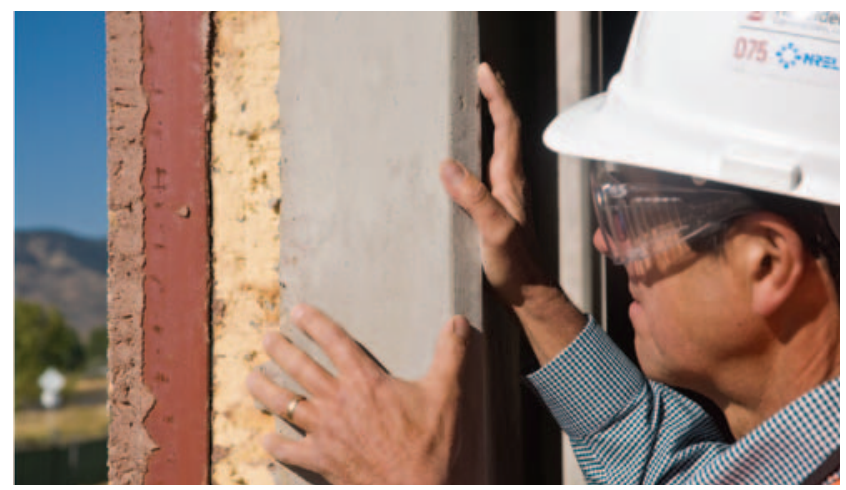

The precast panel's exterior keeps the weather out and helps regulate the interior temperatures. Photo by Patrick Corkery, NREL/PIX 16763

\section{Daylighting and Light-Reflecting Devices}

Daylight was one of the most powerful factors driving the design of the RSF. The building's "lazy H" configuration evolved in response to the need for daylight penetration deep into the building. A combination of extensive computer modeling and careful selection and placement of windows and light-reflecting devices produced a building in which nearly all occupants are within 30 feet of a window.

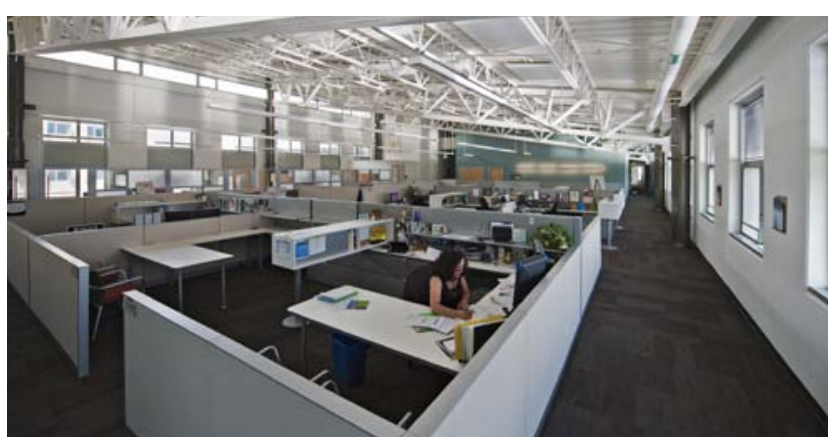

Daylit interior of top floor.

Photo by Dennis Schroeder, NREL/PIX 17904

On the south facade, overhangs shade the lower vision glass. Light enters through the upper daylighting glass and highly reflective louvers direct it toward the ceiling and deeper into the space. The north glazing is not shaded because the softer and more diffused north light does not usually create glare problems.

When daylighting is insufficient, energy-efficient, $25 \mathrm{~W}, \mathrm{~T} 8$ electrical lighting provides a minimum of 30 foot candles at each desktop. Manual switches, photo sensors, and occupancy sensors ensure electric lighting is on only when daylighting cannot supply adequate light. (LED) task lights, each of which consumes only 3 watts, provide localized electric lighting. The control concept for the RSF is to encourage occupants to turn their lights on if daylighting is insufficient and to turn them off when they leave the space. Vacancy sensors turn the lights off if the occupants do not.

The designers selected the interior acoustical treatments, furniture, and paints with daylighting in mind. The paint on the interior wall surfaces and ceilings has the highest possible reflectance, exceeding $80 \%$. Highly reflective acoustical ceiling panels maximize daylight distribution. The low-wall cubicles and office furniture are covered in light colors to reflect light. In addition, the cubicle walls are only 42 inches tall, so daylight can reach deep into the spaces. Daylighting provides all required lighting during sunny sky conditions, exceeding 30 foot candles. 


\section{Triple-Glazed Windows with Individual Overhangs}

The designers chose window sizes and glass combinations that would maximize daylighting but minimize glare as well as unwanted heat loss and gain. The glazing in each of the windows is tuned to its function. All the vision glass on the north and south sides of the building is triple glazed, and thermally broken window frames increase the energy efficiency of the units.

Windows on the north elevation are slightly larger than those on the south elevation, because the north light is more diffuse and less prone to glare. To reduce glare on the south facade, sunshade overhangs shade the lower vision glass.

The east and west elevations feature thermochromic and electrochromic glazing, respectively. Thermochromic glazing resists heat transfer to reduce heat loss, and electrochromic glazing tints in response to a small electric current to reduce heat gain.

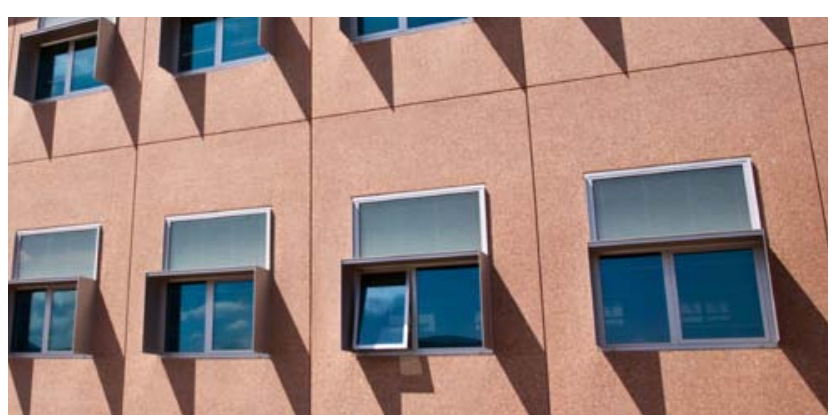

RSF south windows with overhangs.

Photo by Patrick Corkery, NREL/PIX 17412

\section{Light Louvers and Sunshade Overhangs}

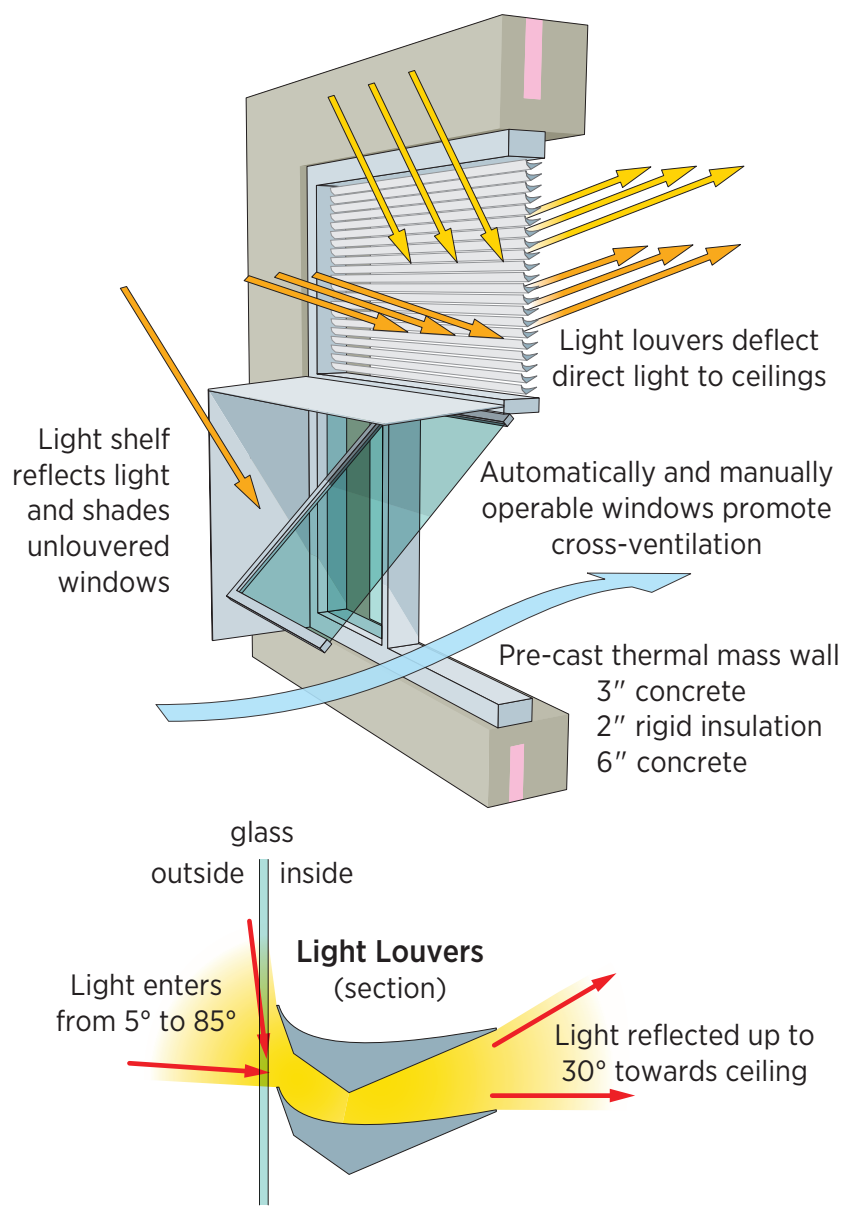

A light louver daylighting system reflects sunlight to the ceiling, creating an indirect lighting effect. Fixed sunshades limit excess light and glare. I/lustration from RNL

\section{Operable and Automatic Window Controls}

A unique feature of the RSF relative to other large office buildings is that during mild weather, occupants can open the windows to provide natural ventilation. On both the south and north elevations of the building, the lower windows can be operated both manually and automatically. On the north elevation, the upper windows can be operated automatically.

A workstation-based task manager interface notifies occupants when conditions are optimal for natural ventilation and windows may be opened. The automatic upper north windows are controlled and operated primarily to support nighttime precooling. 


\section{Radiant Heating and Cooling}

Both office wings are heated and cooled by a radiant ceiling slab, using water heated by NREL's Renewable Fuels Heating Plant (central woodchip boiler) and cooled by high-efficiency chillers that provide cool water on the NREL campus. The building's heating and cooling system features 42 miles of radiant heating tubes that run through the ceilings on each level. These water-based systems allow a great reduction in fan power. Because they are separate from the ventilation system, there are more opportunities for optimization.

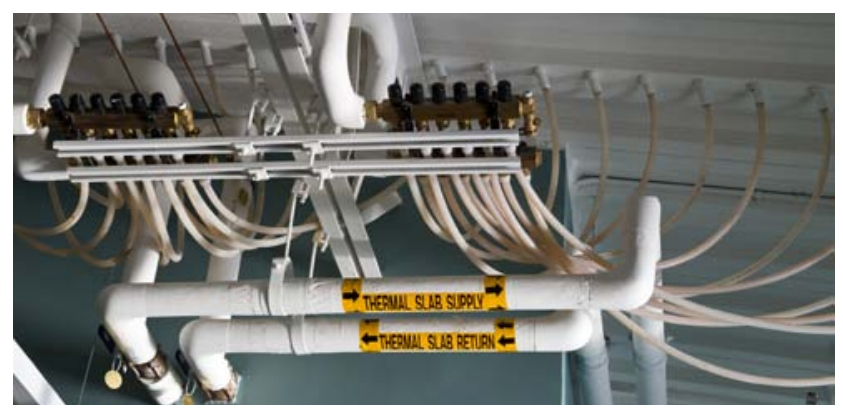

Forty-two miles of tubing run through the RSF ceilings to provide radiant heating and cooling. Photo by Dennis Schroeder, NREL/PIX 19443

\section{Under Floor Displacement Ventilation System}

A dedicated outdoor air system (DOAS) and natural ventilation provide ventilation for the RSF. Ventilation air is distributed by an under-floor air distribution (UFAD) system with swirl diffusers. During mild weather, operable windows provide natural ventilation.

When conditions do not permit natural ventilation, the DOAS provides mechanical ventilation. The DOAS is coupled with the UFAD system, which provides ventilation air at low pressure and velocity, reducing fan energy consumption. Separating the space conditioning and ventilation functions allows the air systems to be downsized relative to a standard forced air system. Demand-control ventilation further reduces energy consumption, and carbon dioxide sensors respond to occupancy and control ventilation when needed.

When dry Colorado summer conditions permit, evaporative coolers provide cool ventilation air. Finally, a sensible heat recovery system captures either warm or cool air from the exhaust air system to precondition the outdoor air, and the transpired solar collector preheats ventilation air during the heating season.

\section{Efficient Elevators}

The RSF features low-energy elevators rather than the standard hydraulic elevators commonly seen in low-rise office buildings. The elevators have energy-efficient fluorescent lighting, and both the light and the fan turn off when the elevator car is unoccupied.

\section{Energy-Efficient Data Center}

NREL's new highly energy efficient data center in the RSF was designed to minimize its energy footprint without compromising needed service quality. In typical data centers, including NREL's old data center located in leased office space, energy consumption results from racks of servers radiating heat, while icy air blows through the room to cool them.

Because NREL is located in a climate that is favorable to "free cooling," the RSF's cooling system was designed to minimize the use of traditional air conditioned cooling and instead use direct air and evaporative cooling methods for almost the entire year, except for the most hot and humid days.

The equipment racks for the data center have been arranged in a hot aisle/cold aisle configuration, with hot aisle containment. The data center's airflow is managed to keep hot and cool air from mixing, which minimizes the cooling requirements. Air from the hot aisle is extracted from the data center for reuse in the RSF when needed.

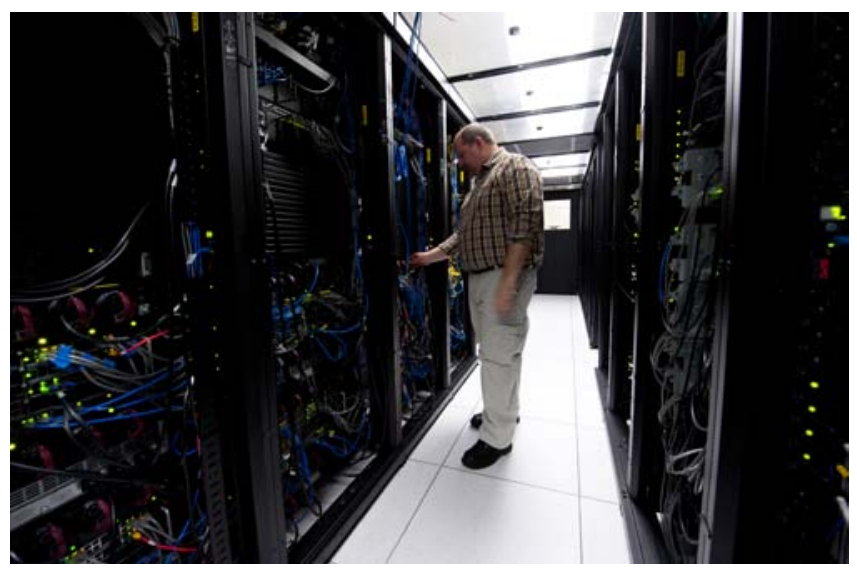

The RSF data center features an extremely low power usage effectiveness ratio of 1.13. Photo by Dennis Schroeder, NREL/PIX 18780 


\section{Lowering the Power Usage Effectiveness}

Power Usage Effectiveness (PUE) is the industry standard metric used to measure the energy efficiency of data centers, including the combined power usage from cooling, power systems, and equipment. PUE is calculated as a ratio using the formula shown below:

PUE $=\frac{\text { Cooling }+ \text { Power }+ \text { Equipment }}{\text { Equipment }}$

The PUE for NREL's previous data center was estimated to be 3.3. In contrast, the measured PUE for NREL's data center in the RSF is about 1.13 as shown in Figure 2. The extremely low PUE is unique among data centers worldwide.

\section{FIGURE 2 Data Center Comparisons}

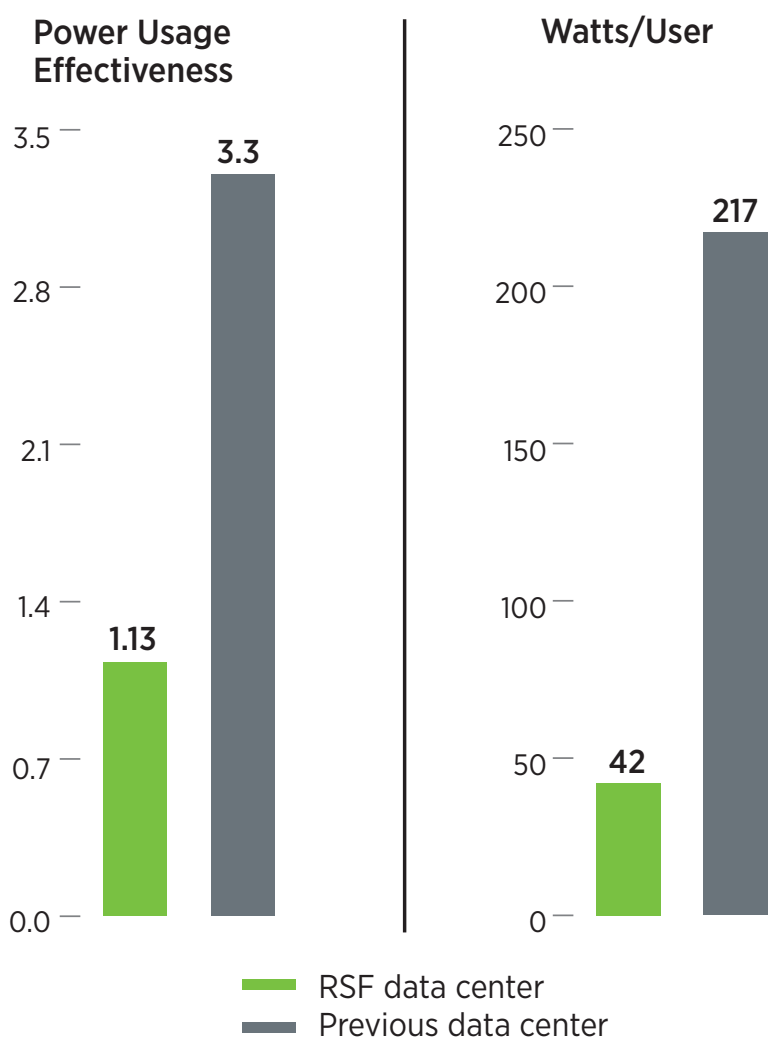

This figure compares watts per user for NREL's old data center with the RSF data center. Moving from NREL's old data center to the RSF data center resulted in a $82 \%$ reduction in watts/user. Figure by Stacy Buchanan, NREL

\section{Comparing Watts per User-a Measure of Success}

PUE only measures how well an organization has optimized its energy use for data center cooling and power systems. It does not take into account efforts to optimize energy use for servers, storage, and network infrastructure running within the data center. Comparing watts per user for total data center power consumption provides a more comprehensive evaluation of overall data center energy efficiency.

\section{"A data center is typically considered world class when the PUE reaches 1.3-we've redefined world class"}




\section{On-Site Photovoltaic System}

The RSF roof has a south-facing 10-degree slope, and a standing seam metal roof that offers an optimal mounting surface for a rooftop photovoltaic (PV) system.

The roof is covered with $450 \mathrm{~kW}$ of PV panels that are more than $17 \%$ efficient. The rooftop array alone will not offset the RSF's energy needs, so several adjacent parking structures will be covered with additional PV. The combination rooftop array and parking structure arrays will provide $1.6 \mathrm{MW}$ of PV to offset all the RSF's annual energy needs.

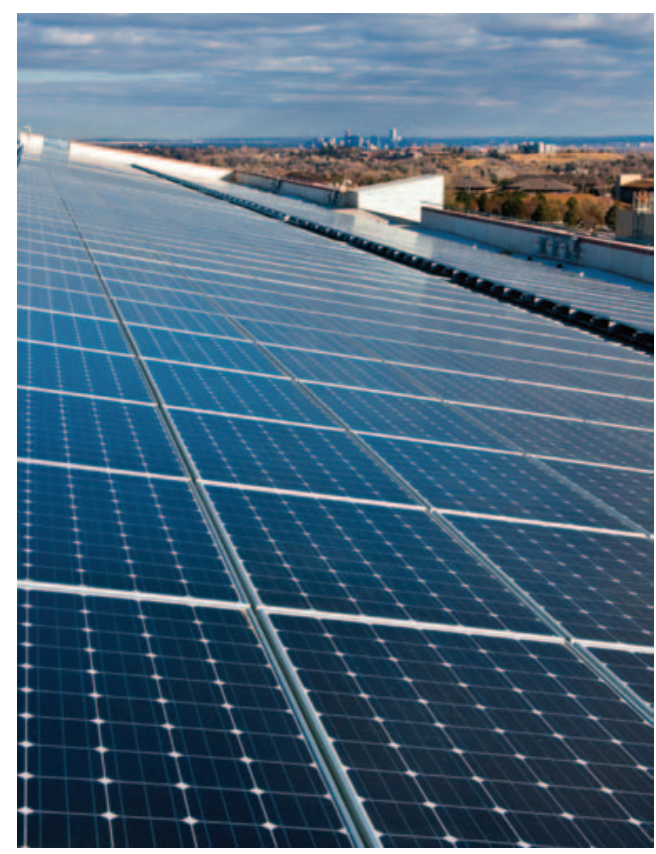

The RSF's rooftop photovoltaic panels will help offset the energy requirements of the building.

Photo by Dennis Schroeder, NREL/PIX 18828

\section{Materials}

One of the first features you notice as you walk up to the RSF is a series of gabion walls that run through the site and courtyards. The excavation activities for the building uncovered a large quantity of significantly sized rocks. Rather than hauling them away by the truckload, they were reincorporated on site and used to build retaining walls and low site walls.

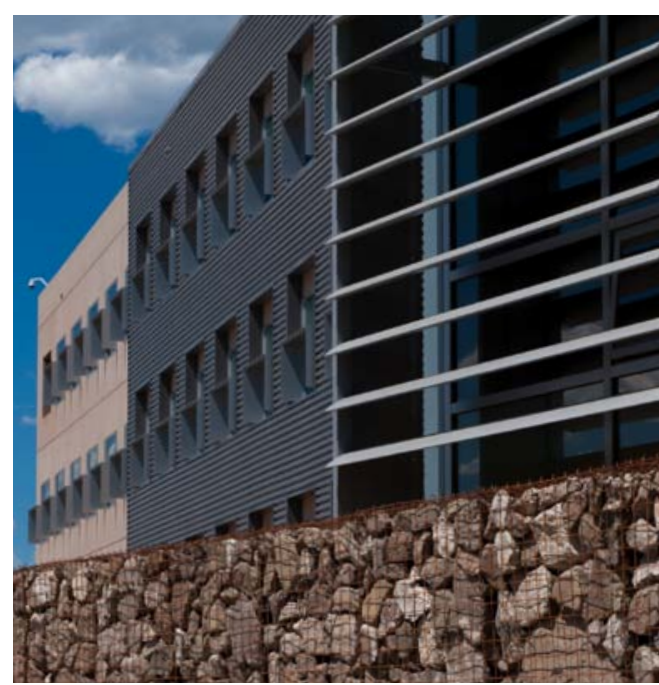

Gabion walls. Photo from Frank Ooms Photography

The interior two-story lobby wall features beetle-kill pine, which was milled from wood killed by the pinebeetle infestation that is spreading throughout Colorado and the region because the warmer summers are not keeping the beetle numbers in check. Countertops are made with a durable rapidly renewable material—sunflower seed hulls.

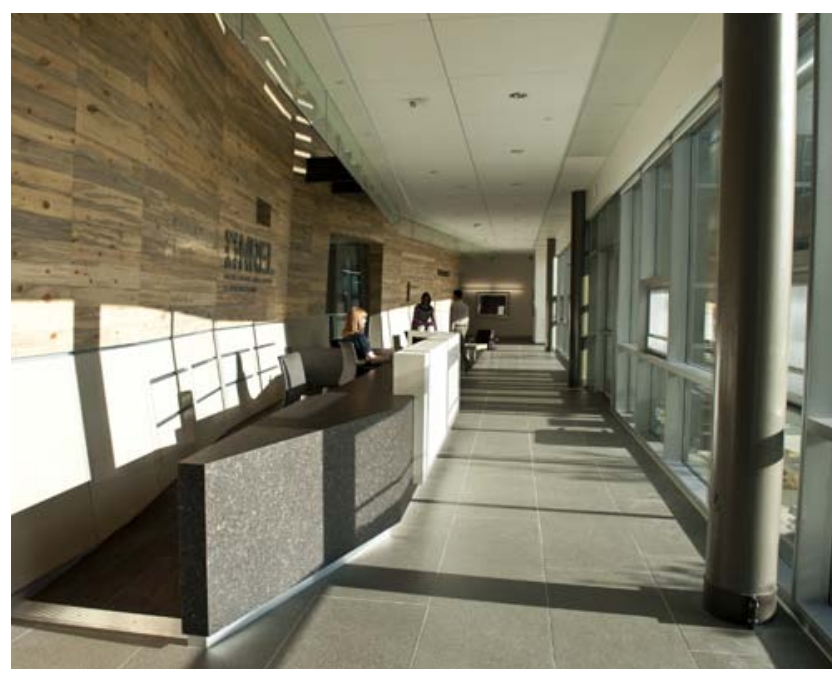

NREL's lobby features walls faced with pine beetle wood, countertops made from sunflower seed hulls, and steel columns made from reclaimed natural gas pipe. Photo by Dennis Schroeder, NREL/PIX 17653 
In addition to the many innovative material applications, a rigorous effort was made to reduce the use of virgin raw material and divert a significant amount of construction waste from going to the landfill.

\section{Water Balance}

The water system design at the RSF respects and works with the natural hydrology of the site and uses a diverse array of water use reduction strategies to approach water balance. Because of Colorado water laws, the project is not allowed to harvest rain water or employ other water reuse strategies. However, the total annual design water for the site is 791,202 gallons, including all building and irrigation uses. This is just less than the quantity of rain that falls on the roof area of the building in a typical year.

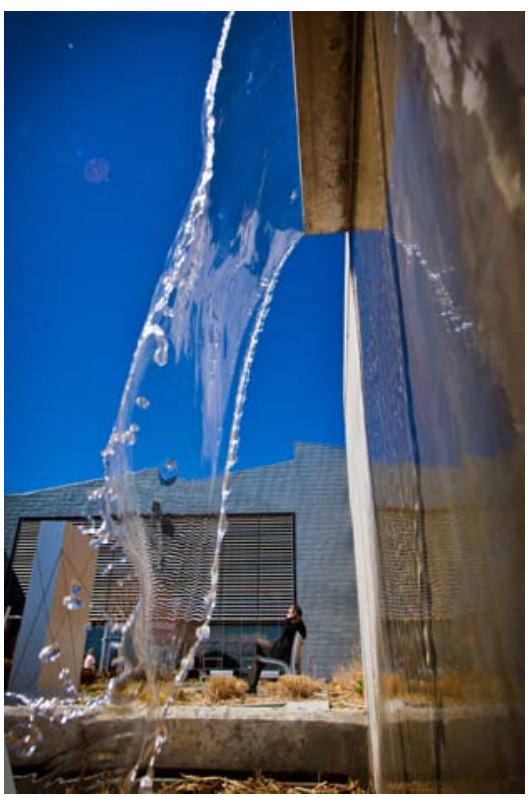

Water flows off the RSF roof, into the down spout, and then into catch basins lined with crushed glass. The water running through those troughs waters the trees and plants as it goes, providing much-needed supplemental water to the RSF vegetation.

Photo by Dennis Schroeder, NREL/PIX 18639
Strategies include:

- Native and adaptive grass and shrub species

- Drip irrigation

- Irrigation zones based on exposure and water frequency

- Satellite-based "smart" irrigation controller

- Bioswales and connection to the campus's arroyo

- Porous paving

- Roof drainage is collected in rain gardens

- Waterless urinals

- Low-flow lavatories

- Low-flow showers

\section{Achieving LEED ${ }^{\circledR}$ Platinum}

The Leadership in Energy and Environmental Design (LEED) Green Building Rating System is the preeminent program for rating the design, construction and operation of green buildings. Out of the 69 total possible points, the RSF project achieved all 59 targeted LEED points including those for site selection, energy, materials and resources, and innovation. This was more than enough to achieve LEED Platinum and it was achieved at no additional cost. The RSF achieved all 17 out of 17 possible points in the Energy and Atmosphere category.

The RSF now has the highest LEED score of the 10 federal facilities that have earned the LEED Platinum rating for new construction.

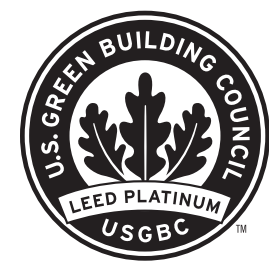

\section{“This is the most rewarding project that we've ever completed in terms of transforming the commercial buildings industry. The impact that the industry could see from this project is enormous."}




\section{Owner Roles and Responsibilities}

\section{DOE/NREL's Integrated Project}

\section{Team}

In the case of the RSF, the owner was not represented by a single person, but an Integrated Project Team (IPT) representing a variety of disciplines. IPT members are DOE and NREL professionals who support the successful execution of the RSF Project.

The IPT roles and responsibilities include:

- Supporting the NREL Project Manager and Federal Project Director

- Supporting development of the project acquisition strategy

- Supporting identification, definition, and management of required project interfaces

- Supporting development of appropriate and adequate scope, schedule, and budget parameters of the project

- Supporting monthly reviews and assessments of project performance

- Participating in project reviews, audits, and appraisals

- Supporting the development and review of Critical Decision (CD) packages

- Providing review and comments on project deliverables

- Reviewing change requests and supporting change control boards

- Providing support of the preparation, review, and approval of project completion and closeout documentation.

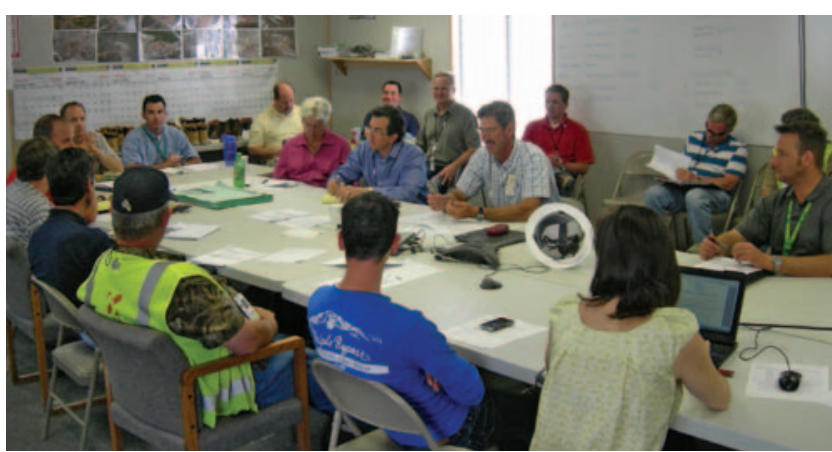

The DOE/NREL Integrated Project Team met weekly with the DB team for several years. Ongoing teamwork was one of the keys to the RSF's success. Photo by Nicki Johnson, NREL/ PIX 20830

\section{IPT Members}

Federal Project Director - Greg Collette. The Federal Project Director is the DOE representative responsible for the development and implementation of the RSF Project at NREL. Activities included:

- Coordinating the execution of the project with EERE and the Office of Engineering and Construction Management to ensure good project management strategies were followed

- Coordinating with NREL project manager to plan, implement, and complete project

- Overseeing the Project Execution Plan developed by NREL project manager

- Overseeing project objectives, scope, cost, and schedule

- Overseeing project funding and authorizes project activities

- Overseeing the design; construction; and environment, health, and safety efforts performed by NREL

- Serving as single point of contact between DOE and NREL staff.

Project Manager - Eric Telesmanich. The NREL Project Manager is responsible for the project scope, schedule, and budget, along with the planning, managing, and reporting of all project activities. The Project Manager is also responsible for all quality and environmental and safety aspects of the project. 
Construction Manager - Carl Cox

Project Engineer - Bret Cummock

Contract Administrator - Karen Leitner

Programming Point of Contact - Nancy Carlisle

Commissioning Point of Contact - Sara Farrar-Nagy

Commercial Buildings Representatives - Paul Torcellini and Shanti Pless

Sustainability/LEED ${ }^{\circledR}$ Representative - Nancy Carlisle

Financial Analyst - Patty Jones-Arnold

Maintenance and Operations Control Engineer Joe Drexler

Environment, Health, and Safety Point of Contact Shawn Bradfield

Other subject matter experts from NREL and DOE participated in IPT activities, including weekly project meetings. Staff representing security, quality, information technology/data center issues, and communications advised the IPT throughout the project.

As in-house experts in commercial building energy efficiency, several NREL researchers were active members of the IPT from the very early planning stages. Their interest in the RSF went beyond energy efficiency to comfort and functionality, both as a research exercise and as a practical matter - they would later move into the completed RSF.

\section{Design Advisory Board}

A Design Advisory Board (DAB) provided advice and counsel to DOE and NREL throughout the project regarding planning documents, activities, and construction documents. Members were external to NREL, DOE, and EERE and included the lead architect, landscape architect/urban planner, citizen/community member, and commercial architect.

The DAB's roles and responsibilities included:

- Advising NREL on plans related to facilities and site development

- Reviewing proposed designs for NREL facilities for compatibility with NREL's most current design standards, site development plans, and similar documents

- Providing advice and recommendations to NREL.

\section{Source Evaluation Team}

NREL adopted the source selection methodology as defined by the Design-Build Institute of America (DBIA) beginning in 2007. The Project Manager led the formation of a Source Evaluation Team (SET). This small team, which included both NREL and DOE employees who were also on the IPT, was responsible for:

- Establishing the RFP general selection criteria;

- Issuing the pre-solicitation Notice via FedBizOps;

- Completing detailed selection criteria and weighting; and

- Issuing a shortlist recommendation of three firms for the final DB contract. 


\section{Acquisition Strategy}

In FY2006, EERE appropriated \$9.9 million to begin an eight-year, phased build-out of the NREL's South Table Mountain (STM) complex, specifically for the RSF. In February 2007, the 110th Congress approved the Joint Resolution making FY2007 appropriations, including a $\$ 300$ million increase, to EERE in recognition of the urgency of the nation's energy and economic security goals. Congress directed DOE to identify and prioritize its proposed investments, which included full funding for the previously approved RSF project.

The RSF project total cost estimate was $\$ 72.9$ million (\$9.9 million in FY2006 and \$63 million in FY2007) with a total project cost of about $\$ 80$ million.

\section{Range of Alternatives to Consolidate Staff}

DOE developed three alternatives to address the need to consolidate operations at the STM site and terminate existing leases for support operations.

\section{Standard Leasing without Ownership (Base Case)}

This alternative represents a continuation of EERE's historic practice of leasing from the private sector at a location near the STM site without the option for ownership of the asset.

\section{Lifecycle Cost Range: \$173M-\$231M}

\section{Acquire the Capability Using Appropriated Funds}

This alternative involves co-locating a facility on DOE's STM site using appropriated funds.

\section{Lifecycle Cost Range: \$68M-\$91M}

\section{Acquire the Capability Using Private Sector Funds}

This alternative involves co-locating a facility on or adjacent to DOE's STM site using private sector funds in a project finance arrangement.

\section{Lifecycle Cost Range: \$98M-\$130M}

The cost of the range of alternatives was analyzed using a discounted, life-cycle cost model as prescribed in the Office of Management and Budget Circular A-94. The analysis period was 30 years to match asset life.

The RSF business case analysis determined that alternative 2 , acquisition with appropriated funds, was the most cost-effective approach for the government to meet its critical mission need at NREL.

\section{The Decision to Use Design-Build}

While NREL had been successful with the traditional Design-Bid-Build project delivery method, both NREL and DOE wanted to create value well beyond the dollars available by unleashing the creativity of the design team.

The study "Selecting Project Delivery Systems, Comparing Design-Build, Design-Bid-Build and Construction Management at Risk" (Victor Sanvido and Marck Konchar, 1996), showed that DB projects as a whole had the least cost growth, no schedule growth, and the highest quality rating of all three methods. DOE and NREL took DBIA training to better understand the performance-based DB method.

\section{Design Charrette}

In June 2007, DOE and NREL hosted a two-day national design charrette for the RSF. The overall objective was to bring together a diverse set of stakeholders, subject matter experts, and users of the facility to develop one integrated set of recommendations to be used as input to the RFP for the DB process.

A secondary objective was to host a participatory process to solicit ideas from national experts, DOE's EERE programs, and local participants to inform the project design, create goodwill, and build consensus regarding a shared set of objectives for the project.

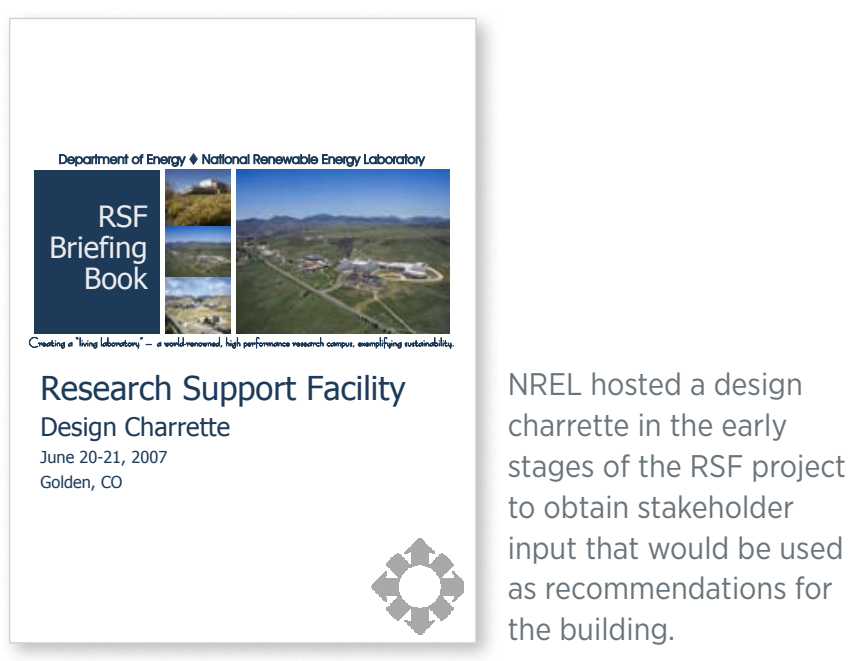




\section{Design Charrette Recommendations}

The group agreed that it was not possible to meet all of the project scope originally identified in the DOE Expectations letter within the fixed budget. They recognized the importance of DOE and NREL working together to prioritize the project requirements.

For the DB contract, the group acknowledged that the project outcome would be dependent on the internal contract preparation work. They recognized the need to develop both the building program (defining the spaces needed and the functional adjacencies) and a detailed set of requirements for the RSF project (including desired requirements for siting, image, energy and sustainability features, program, required mock-ups, etc.) prior to issuing the Request for Proposals (RFP).

The RFP requirements needed to address both the quantitative and qualitative aspects of the space. To meet the completion date, the charrette participants set an internal deadline of August 24, 2007, to issue the RFP to a short list of bidders. Two RFP contract Appendices were necessary: 1) a detailed building program and 2) a detailed set of building requirements.

NREL and DOE needed to define the building requirements in sufficient detail so they were clear to the DB contractor. However, they would also need to be written to allow the DB team to apply their own creativity to develop the overall DB solution.

In addition, recognizing antinomies - contradictions between two apparently equally valid principles or between inferences correctly drawn from such principles - was an important concept that was discussed as applied to the RSF project requirements.

Contradictions identified included:

- Budget versus scope

- Need for fixed versus flexible spaces (workspaces that can be reconfigured as offices grow or merge, conference rooms that can accommodate multiple configurations)

- Fixed versus variable program requirements (i.e., the number of workspaces might be fixed, but number of conference rooms might be variable)

- Time/scope (i.e., current needs versus future needs)

- Mission-critical versus support space

- Needs versus wants
- The charrette process helped engage stakeholders and get issues on the table early in the process. Participants raised key issues at the charrette that needed further discussion prior to selecting the DB contractor.

- Budget versus scope: DOE and NREL would need to make hard choices regarding the building programming prior to engaging the DB contractor. As the building owner/client, DOE and NREL needed a clearly articulated vision for both quantitative and qualitative building attributes that was achievable within the budget.

- Balance the need for the number of workspaces against other elements of the program that enhance human productivity aspects of the workplace: The success of the building was defined not only by meeting defined qualitative goals (such as number of work spaces) but also by the quality of the workspace and its ability to enhance productivity to recruit and retain staff.

- Ensure that the program meets the mission critical and functional needs for space: Besides providing mission critical needs and functional needs for interior spaces, the RSF also needed to provide an outside environment for people conveying a visual message to the public about DOE's and NREL's missions.

- Energy versus siting versus budget: Achieving the energy goals would require optimal building orientation for daylighting. Building form, floor-to-floor height, and floor layout all impact the ability to maximize natural lighting. The interrelationship between energy, building siting, and impact on budget would be important to understand and articulate in the requirements.

- Time pressures: Balance the desire to build quickly versus the need to design and detail it for aesthetic as well as energy use considerations.

\section{"The work we did and the decisions we made during the Design Charrette process provided a solid foundation for the RFP." \\ - Nancy Carlisle, NREL Programming and Sustainability Point of Contact}




\section{Defining Performance Objectives}

DOE/NREL's design-build (DB) planning for the RSF included the Design-Build Institute of America's (DBIA) best management practices for selection. Their planning included the use of the 3PQ Acquisition and Management System ${ }^{\odot}$ - an organizational management system developed by DesignSense, Inc. and designed for use by owners and Owner Representatives. The Source Evaluation Team (SET) defined three tiers of performance objectives for a performance-based request for proposals (RFP):

- Mission Critical (scope that must be achieved)

- Highly Desirable (scope that the owner believes can be achieved)

- If Possible (scope that is valued by the owner).
Throughout the project, the DBIA best practices helped the IPT understand the nuances of how to make a DB project successful. Just two months after the design charrette, DOE/NREL commissioned the DBIA to conduct a week-long "boot camp" on the acquisition strategy to familiarize the IPT with the finer points of the DB process.

DOE and NREL knew that choosing the right DB team would be essential to the success of the RSF project.

\section{"We followed the DBIA's best practices for performance-based design build; projects are done quicker, cost less, and we get better quality."}

\section{TABLE 1 RFP Performance Objective Tiers}

\begin{tabular}{|l|ll}
\hline Importance & Objective \\
\hline $\begin{array}{l}\text { Mission } \\
\text { Critical }\end{array}$ & - Attain safe work performance/safe design practices \\
& - Earn LEED" Platinum designation \\
- Attain ENERGY STAR First "Plus," unless other system outperforms
\end{tabular}




\section{Design-Build Defined}

In $\mathrm{DB}$, the building owner contracts with a single legal entity - the design-builder - to provide a completed building based on the owner's design criteria. Unlike Design-Bid-Build and Construction Manager at Risk methods, the designer/builder controls both the design and the construction process.

The owner develops a clear, comprehensive RFP that outlines the expectations for the project, and the design-builder assumes complete responsibility for delivering the project as specified in the RFP, on time and within budget.

\section{Performance-Based Design-Build}

In performance-based DB, the owner does not rely on "prescriptive" plans and specifications to define the scope of the project. Instead, the owner focuses on defining the problems to be solved, and the designbuilder is tasked to develop solutions

This delivery method assigns control and accountability differently from the traditional design-bid-build method, in that the owner sets a firm price for the project, develops documents, and prioritizes performance expectations in a RFP, and then invites design-builders to propose solutions that best meet the performance expectations. The owner then selects a design-builder to complete the project for a fixed price. The successful design-builder is responsible and accountable for designing, building, and delivering the project on schedule and for the fixed price.

\section{The Benefits of Using Design-Build}

Historically, building owners would solicit an architectural firm and, once a design was completed, contract separately with a builder for its construction. By its nature, this method put the architect and builder at odds. Inevitably, the builder would blame the architect for poor design, and the architect would blame the builder for careless construction.

The DB project delivery method solicits a teaming approach between the architectural and construction communities at the beginning of the project to offer best value bids for specified owner objectives. A form of performance-based contracting, a DB contract has numerous advantages detailed below. The objective is to create an instrument that motivates marketplace providers to offer greater value for the owner's asset, with value defined as performance over time acquired at a competitive cost.

- DB and Singular Responsibility: With both design and construction in the hands of one entity, there is a single point of responsibility for coordination, quality, cost control, and schedule adherence; thus, avoiding finger pointing between designers and builders for errors or shortcomings. This singular responsibility removes the owner from the role of referee and allows for productive time spent focusing on other project needs and timely decision making.

- Quality: The singular responsibilities inherent in the DB process serve as motivation for high quality and proper performance of building systems. Once the owner's requirements and expectations are documented (and agreed to by the DB entity) in terms of quality and performance, it becomes the designbuilder's contractual responsibility to construct a facility that meets or exceeds those criteria.

- Cost Savings and Value: Successful DB enables the creation of project value well beyond the traditional project cost. DB can trade off performance and cost to produce the most optimal design solution. When design and construction professionals work and communicate as a DB team, alternative materials, building systems, and methods are evaluated efficiently, accurately, and creatively. A comprehensive knowledge of labor and material costs, coupled with an awareness of the cost relationships between the various project components, allows the DB team to increase the project's value while reducing the overall cost.

- Time Savings: Because design and construction can overlap, and because general contract bidding periods and redesign time are eliminated, total design and construction time can be significantly reduced. In a more traditional DB project, design and construction can overlap more based on the design and construction team relying on standard industry assumptions, reusing existing specifications with minimal modifications, etc.

For a very high performance building like the RSF, design and construction overlap must be planned and limited to avoid locking down aspects of design that require extensive research, design development, and coordination. 


\section{"The design-build strategy differs dramatically from tradition design- bid-build in that it looks for solutions versus trying to work off of specifications. It really requires a strong design-build team relationship, and a progressive approach to isolate and control risk for all teams."}

- Risk Management: After the project requirements are outlined in the RFP, the owner receives multiple design solutions and cost proposals representing the best thinking of several design-builders. These alternative designs provide the owner the opportunity to better weigh the risks and benefits of several competing proposals before committing to any single design solution. Change orders due to errors and omissions in the construction documents are eliminated because their correction is the responsibility of the designbuilder, not the owner. The aspect of assigning risks to those best capitalized, staffed, and experienced to assume and manage them is another advantage of the DB project delivery method.

- Innovation: Because performance requirements replace prescriptive specifications, DB teams are free to develop creative and innovative responses to a stated problem.

- Alternatives: The performance-based DB acquisition strategy is the only procurement model that provides the owner a choice of distinct alternative "solutions" prior to award of the contract. In the case of the $\mathrm{RSF}$, the owner received three distinct proposed solutions in response to the RFP.

\section{Acquisition Contracts}

Acquisition for the RSF included five contracts, three of which were awarded in the acquisition planning phase. The fourth was the DB contract. To reduce the risks involved in not properly defining the detailed performance requirements and project scope, the project team sought expert assistance for architectural programming, RFP development, and management oversight.

NREL executed all acquisitions for DB services, support, implementation, testing, inspection, telecom terminations, and moves. DOE performed oversight of all NREL activities.
Every solicitation was conducted using a Best Value Selection, resulting in an award that was most advantageous based on the best combination of technical merit and price.

\section{The Design-Build Procurement Process}

One of the mission critical objectives of the RSF was that the design be easily and affordably replicable by other federal agencies.

To accomplish the project, DOE/NREL determined that the best way for them to achieve these high-risk objectives was to use performance-based design-build to procure the facility. Performance-based design-build is a robust delivery method, and when procured with the seven best practices, both highly unusual and basic goals can be achieved.

These seven best practices of design-build of designbuild procurement have been compiled by Northstar Project Management, Inc. from the Design-Build Institute of America's 1996 Manual of Practice. The Federal Acquisition Regulation (FAR) and the OMB Circular A-111 Sub Part b:

1 Two-Phase Competition: DOE/NREL chose to use a two-phase competition as allowed by the FAR 36.3. In the fall of 2007, they offered a Request for Qualifications that generated eight responses, then offered a Request for Proposal to the shortlisted firms.

2 Shortlist to Three: Also in accordance with FAR 36.3, the RFP went to only three firms. DOE/NREL believed they would receive a more focused, innovative competition with three firms, they wanted to shorten the time to award by reviewing only three proposals, and they believed that if one firm dropped out, two firms would still give them the needed competition for a federally funded job. 
3 Interim Interviews: DOE/NREL held interim interviews during the $\mathrm{DB}$ competition. The purpose of the interviews was to make sure that each DB team was on the right track. If the design was not in accordance with the RFP, the team would receive feedback and would have a greater chance to win the project by adjusting their design to meet the RFP requirements.

4 Performance Specifications: DOE/NREL used narrative performance specifications based on the Construction Specifications Institute's Uniformat II Standard. Bridging documents were not used. The use of performance specifications shifted the risk of designing to budget to the DB team, while allowing them the freedom to solve the cost/budget/schedule problem, as long as their solution met the performance criteria.

5 Stipends: For this project, DOE/NREL offered stipends of $\$ 200,000$ per non award team. Teams spent up to $\$ 1$ million to compete on this project, so the stipend went a long way to help mitigate costs for the two teams that did not win. Shortlisting to three firms allowed the owner to pay fewer stipends as there were only two non-award teams.

6 Award Fee Plan of Incentives: Per the FAR Sub Part 16.4, DOE/NREL offered an award fee plan of incentives valued at $\$ 2$ million. The Award Fee is only offered for superior performance by the designbuilder in six separate stages:

- Preliminary Design

- Design Development

- Construction Documents

- Construction

- Closeout

-12-month post occupancy
Each of the six stages has unique criteria suited to each stage. The DB team is given either a Superior, Excellent, Satisfactory, or Unsatisfactory rating once a month, so they may improve performance and then award the incentive at the end of each period. NREL firmly believes in incentives for DB teams as it creates a win-win situation for both the owner and the DB team, and it manages risk for the owner.

7 Best Value Selection: Best value means the owner may select a higher price if greater value is offered to the owner. DOE/NREL awarded the RSF project to the best value DB team. 


\section{Acquisition Planning}

\section{Architectural Planning}

NREL hired a consultant with expertise in architectural programming to help develop the RSF programspecifically to help NREL define the space requirements for common areas and office needs in the RSF. Because it is the owner's responsibility to prioritize and communicate their needs to design teams, this is a critical step for projects using a firm fixed price, DB contracting method.

Unidentified needs resulting in design changes later in the construction process are costly to the owner, extremely disruptive, and can derail the integrated design and construction taking place. Needs identified later in the process are also likely to cause schedule delays in addition to financial implications. They can also create conflicts to the facility's performance goals and strain the relationship between the DB team and the owner.

\section{RFP Development}

NREL held a limited competition with industry experts to assist them with developing the RFP document. Because architectural/construction teams based their firm fixed price bids solely on this document, the RFP had to be clear and comprehensive. This requirements document is the sole basis for soliciting design-builder's bids and their proposals provide the basis for selecting the winning team.

DOE/NREL retained the services of DesignSense, Inc., a strategic acquisition planning and program management provider, to help write the RFP. Unlike many owners, DOE/NREL has the technical expertise to develop energy performance goals and support the DB team to meet those goals. However, successful performance-based DB procurement relies on clearly articulated performance goals detailed in an RFP. Therefore, DOE/NREL elected to hire an expert to develop such a critical component of the process.

\section{"With projects of this magnitude,}

there is pressure to get going, but it's critical to spend the time needed up front planning."
Over the course of the RSF project, the IPT developed an appreciation for the importance of developing an accurate RFP. Any changes to the contract would result in an additional cost to the project.

There are many benefits of a clear and complete RFP:

- Helps DB team develop solutions that save time and deliver more for the money

- Avoids legal disputes, especially coming out of the design competition

- Avoids misunderstandings later in the process

- Allows the DB team to quickly move into the process of delivering the building instead of backtracking to find out what the owner really wants.

- Builds the foundation for a good relationship between the owner and the DB team going forward.

Establishing clear project requirements early in the project was critical as well as establishing a realistic project timeline. Contracting with experienced DB implementation experts significantly reduced the time needed to draft a RFP capable of soliciting on-target firm fixed price bids.

\section{Design-Build RFP Components}

- Introduction - Narrative describing goals, project intent, best value

- Procedures - Narrative describing the competitive process, evaluation criteria, incentives

- Program - Occupancy totals, departmental affinities, parking requirements

- Performance Specifications - Technical data, load requirements, energy monitoring systems

- Instruction Notices and Conditions to Offerers (INC)

*Note: A project with an aggressive energy goal should also include detailed assumptions for owner-provided equipment and equipment energy consumption. 


\section{RFP Process}

Developing a performance-based request for proposal was quite a challenge and was a first for DOE and NREL. Achieving the necessary energy efficiency and innovation meant that the owner had to challenge the private sector to come up with the best solutions possible - at a \$64 million total project cost.

Extensive upfront planning by DOE and NREL was critical to the RSF's success. Unlike a traditional design-bid-build approach, the owner invested time up front and early on to ensure that the project definition was as good as possible.

There were three major steps in the RSF's RFP process.

\section{Request for Qualifications}

In early 2007, DOE/NREL published a broad national request for qualifications soliciting the RSF project in very general terms. The prequalification submittals needed to address the following criteria:

- Demonstrated capability to develop an architectural image that is contextually appropriate with the site's natural environment and the owner's identity to showcase energy efficiency and renewable energy technology. Provide examples from previous clients demonstrating capability.

- Demonstrated expertise to design to energy goals. Provide examples of integrated energy strategies from previous clients.

- Demonstrated expertise to integrate environment, safety, and health into the design and construction of office space.

- Provide a minimum of five references from previous clients demonstrating the integration of safe design, construction, and operation.

- A methodology to provide regional knowledge and expertise in such areas as local codes, water laws, and local climate for incorporating the requirements noted within this solicitation.

- Demonstrated expertise to design and construct office buildings to meet the needs of the workforce of today and tomorrow. Provide examples from previous clients demonstrating compliance of workforce needs.
- Demonstrated expertise using an integrated approach for successful completion of DB projects or projects with a similar acquisition approach.

- Provide a minimum of five references from previous clients demonstrating successful completion of DB or similar endeavors.

- Demonstrated ability to collaborate with, and incorporate ideas from diverse expert sources.

- Provide examples from previous projects demonstrating collaboration and incorporation of ideas from diverse expert sources.

The prequalification process generated a list of 10 qualified design/construction teams. DOE/NREL evaluated these 10 teams and then selected three that would be invited to respond to a draft RFP. The following criteria were used in the selection process:

- Design and construction team makeup and past collaboration experience

- Team familiarity with the DB process

- Past LEED ${ }^{\circledR}$ (Leadership in Energy and Environmental Design) experience, meeting energy goals and utilizing renewable energy technologies

- Demonstrated experience in the design and construction of flexible workplace environments

- Conceptual understanding of energy efficiency demonstrated with an architectural image.

DBIA best practice recommends competition among three teams because a team is more likely to fully commit time and resources when the odds of selection are greater. If one competitor drops out, the competitive process remains intact with two teams.

\section{Draft RFP}

DOE/NREL chose three highly qualified teams to respond to the initial draft RFP in late 2007. By issuing a draft RFP, DOE/NREL could jointly review the document with the three shortlisted firms during oneon-one meetings. The three firms reviewed a draft RFP and provided feedback that helped validate the scope, schedule, cost, and clarity of the RFP expectations in consideration of the current RFP market. The overall goal was to improve the initial draft to help the final team achieve the best possible design. 


\section{Final RFP}

The Project Manager and SET incorporated the three firms' comments, made final updates to the RFP, and then issued the final RFP to the same three shortlisted firms in February 2008. The RFP required that each team develop a project plan to demonstrate how the team proposed to achieve the project's key performance goals. This work involved a substantial investment of time and resources for each of the teams.

\section{"Put in a lot of effort to review \\ your short-listed teams. You want to have a high level of confidence in who you pick and that your team has demonstrated design- build experience."}

\section{Design-Build Competition}

The final selection process included several steps:

- The three firms were given two months to prepare their proposals, including a concept design solution for the RSF.

- NREL's SET met individually with each firm during the design preparation to answer questions and ensure that each firm was on course to complete the proposal.

- The SET evaluated the proposals and each team provided an oral presentation. Proposals were evaluated based on the responses to the evaluation criteria.

- The SET completed evaluations and provided its recommendation to the Source Selection Authority, who concurred with the recommendation.

- Those firms that were not selected received a stipend, and DOE retained the rights for the conceptual design work and all other components of the applicants' proposals.

\section{Awarding the Design-Build Contract}

The subcontract was awarded in July 2008 to the DB team of Haselden Construction, a general contracting firm, and RNL, an architecture and interior design firm.

Phase 1 of the DB contract was for preliminary design of the RSF. Focusing on performance goals rather than technical specifications gave the DB team the flexibility and freedom to develop a conceptual design that would meet DOE/NREL's Mission Critical, Highly Desirable, and If Possible key performance goals within the project's budget.

This is the first facility that DOE/NREL procured using the performance-based DB method. Based on the success and lessons learned during the RSF procurement process, new capital assets are being acquired using the DB method.

\section{Design-Build Owner's Representative}

NREL selected an Owner's Representative, Northstar Project Management, Inc., from a broad competition to assist the project manager during the design and construction process, including:

- Developing new internal procedures and policies applicable to design-build such as Design Conformance Reviews, Pay Application Reviews, writing the Award Fee Plan of Incentives according to the FAR

- Providing strategic leadership to support the integration of the DB team with the IPT

- Piloting DOE/NREL's first-ever partnering session

- Facilitating the project's on-time delivery

- Serving as an additional oversight body to help mitigate unidentified risks

- Managing substantiation requirements

- Lending construction management expertise in design review, constructability evaluations, quality oversight, conflict resolution, cost review, and scheduling on behalf of DOE and NREL.

Northstar Project Management, Inc. also provided engineering support during design and construction and third-party commissioning oversight. 
With one firm responsible for providing all of these tasks, DOE/NREL was able to streamline the process and avoid any potential issues associated with assigning responsibility for problems.

\section{"Our third-party owner's}

representative acted as an

independent referee to help

us through some of the design

challenges that we had, answer

our questions, and make sure

that we were being very honest

about our assessment."

\section{-Jeff Baker, DOE-GO Director of Lab Operations}

\section{Award Fee Incentive Program}

To encourage superior performance by the DB team and influence contractor behaviors, DOE/NREL established an award fee pool of \$2 million. This award fee plan of incentives, which follows the requirements of the FAR Subpart 16.4, gives the DB team the opportunity to earn additional compensation for superior performance in the following areas:

- Safety

- Design effort and objectives

- Commissioning

- Workmanship-Quality of all work

- Responsiveness-Problem Solving

- Communication and professionalism

- Timeliness of completion.

The award fee incentive program allows for award fee at the following evaluation stages:

- Completion of preliminary design - not more than $20 \%$ of award fee

- Completion of design development-not more than $15 \%$ of award fee
- Completion of construction documents-not more than $15 \%$ of award fee

- Completion of construction-not more than $25 \%$ of award fee

- Completion of closeout-not more than $20 \%$ of award fee

- 12 month post occupancy - not more than the balance of award fee.

The award fee incentive program allows the designbuilder to "roll over" any unearned award fee to the next stage if they meet certain requirements. This incentivizes the design-builder to continuously improve.

\section{Establishing a New Role for the Building Owner}

One of the most important lessons learned is that DOE and NREL established a new paradigm for their role as the building owner during the DB process. The owner is responsible for stating the architectural "problem" to be solved - the DB team is responsible for finding the "solution." Haselden/RNL was contractually obligated to achieve DOE/NREL's performance requirements stated within the RFP.

\section{Managing Risk}

DOE/NREL chose to make this transition due to the need to manage risk. If the owner made design decisions on the project, they would become legally liable for those decisions. By being a resource for the DB team, and requiring them to make all decisions to conform to the schedule, budget, and quality requirements, the risk for design and construction was transferred to and remained with the DB team.

Once a DB team is under contract, the building owner's role is to verify that the basis of design meets the project's performance requirements. The $\mathrm{DB}$ team is tasked to use their expertise to develop the architectural solution. In the case of the RSF, NREL is a leading expert in high-performance, sustainable buildings. The DB team has enthusiastically drawn from this expertise, though there was a fine line between evolving owner desires and those contractually agreed upon at the project's onset. 


\section{RFP Process Challenges}

Although the overall project and DB contract and process were successful, there were also some challenges along the way that had to be overcome. Haselden/ RNL decided to withdraw early from the project. DOE/ NREL met with the team to discuss their concerns and learned that although they were highly motivated to do the project, they found the project far too risky. Haselden/RNL were concerned that they didn't have enough information to guarantee the total price before design was complete. In addition, Haselden/RNL was unwilling to commit to meeting the RSF's aggressive energy requirements and achieving LEED ${ }^{\circledR}$ Platinum before design had even started.

DOE/NREL originally wanted the design-builder to enter into a contract where the DB team would have $100 \%$ of the project price at risk at the completion of the proposal period. However, they all eventually agreed to $50 \%$ of the fee at risk, bringing the designbuilder back to the table.

\section{Changing to a Two-Phase Contract}

DOE/NREL also agreed to a two-phase contractual process, mitigating the financial risk. The first phase would take the process through preliminary design to give the winning design-build team four months to confirm that they could meet the RFP requirements within the budget. If not, all parties could terminate the contract by mutual agreement. The second phase of the contract would be awarded if they met all of the RFP requirements for the budget and would lead to final design and construction, which was the largest portion of the contract.

\author{
"When we short-listed the three firms, \\ we realized it was too much risk. We \\ heard the feedback and to mitigate \\ the risk, we used an innovative two- \\ phase contract approach." \\ -Karen Leitner, NREL Contract Administrator
}




\section{Integrated Design}

With the DB team of Haselden/RNL selected, the IPT worked together closely through an integrated design approach to fully understand and define every aspect of the project and to review and provide input on the preliminary design, final design, construction, and warranty period. To achieve optimal energy efficiency, each building must be designed, built, operated, and maintained as an integrated system. Integrated design takes advantage of the fact that changes and improvements in the design process are relatively easy to make in the beginning, but get progressively more difficult and expensive as the project progresses.

Integrated design requires close collaboration, good communication, and interdisciplinary work among architects, engineers, operations staff, building owners, and any other relevant players from the beginning of the design process. Participants must discuss the relative importance of various performance issues and consensus must be developed between the owner and the design-builder. Because extra expenses for one system may offset costs in another system, budget constraints should ideally be applied at the whole-building level.

During the design and construction of the RSF, the IPT met regularly with the DB team, and provided input at every stage of the process. The DB team addressed DOE/NREL comments on design throughout the process and discussions continued until resolution was achieved.

\section{“You can’t just design the building, throw in some energy features, and then see how you did. The energy and architecture have to work together to meet the objectives."}

-Paul Torcellini, NREL Commercial Buildings Research Group Manager

\section{Energy Requirements Drove Building Design}

Unlike traditional design - where architecture defines the form and impacts the function of a buildingenergy performance requirements drove the RSF design to meet the aggressive energy goals. Haselden/ RNL, working with Stantec Engineering, used extensive energy modeling to establish the basic building architecture and structure. They determined that two long and relatively narrow structures consisting of an economic ceiling height and repetitive 30 foot long by 60 foot wide modules - with the long axis facing north and south - would maximize building daylighting. This strategy was critical to reducing the need for electric lighting, which is a major end-use of energy in office buildings.

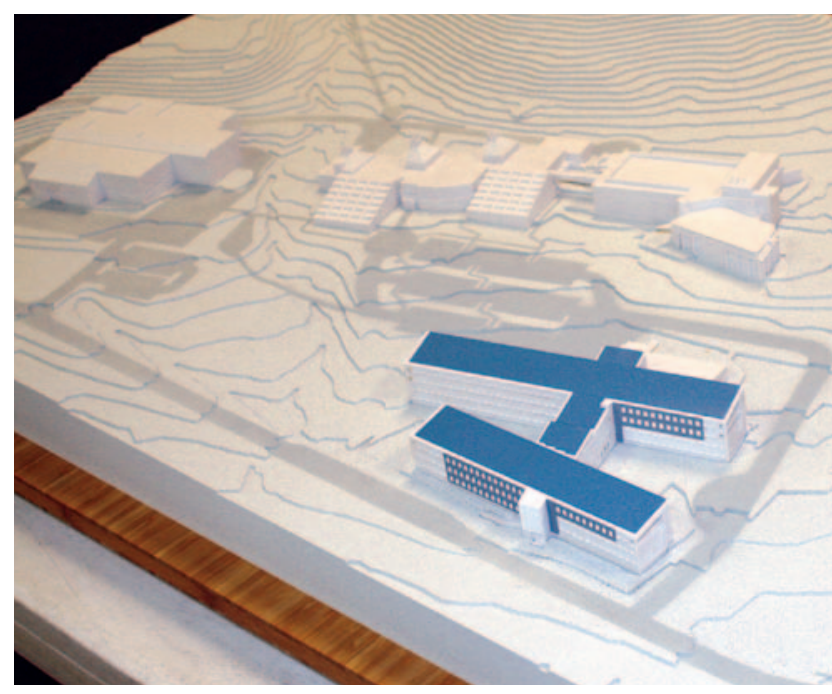

RNL's model shows the "lazy H" shape of the RSF and the long building wings in relation to other existing campus facilities. Photo by Nicki Johnson, NREL/PIX 19445

Once the team established the basic form and orientation of the building, the interior design team developed the layout of the workspace to take full advantage of daylighting and facilitate employee collaboration - a critical component to effective operations. This required light-colored, reflective surfaces throughout the building, low cubicle walls to permit daylight to penetrate deep into the workspaces, and a lighting control system. 
Mechanical, electrical, and plumbing systems were designed to accommodate the energy-efficient design and occupancy needs. This process - energy, form, interior, mechanical - is a change from the traditional approach to design. To support this process, the team performed energy modeling to evaluate the impact of the design on energy performance.

The requirement for close collaboration between Haselden/RNL and DOE/NREL forced all parties to fully understand all aspects of the project and enabled the development of an integrated preliminary design with few unknowns. The project's cost, scope, and schedule baseline, which formed the basis of the firmfixed price DB contract, was established at the end of preliminary design. Under the DB strategy, construction started prior to completion of the final design, reducing project execution time with no additional project risk. Construction of the RSF was completed in approximately 16 months, in June 2010, and all of the designbuild work was completed in just under two years.

\section{Timeline}

A major advantage of the performance-based DB procurement process is that it allows construction to begin before the final design is completed, saving time and money. DOE and NREL committed to adopting the DB process in the spring of 2007, and the RSF opened just over three years later. By using fast-track, concurrent design and construction, both design and construction were completed in 23 months.
TABLE 2 RSF Timeline Highlights

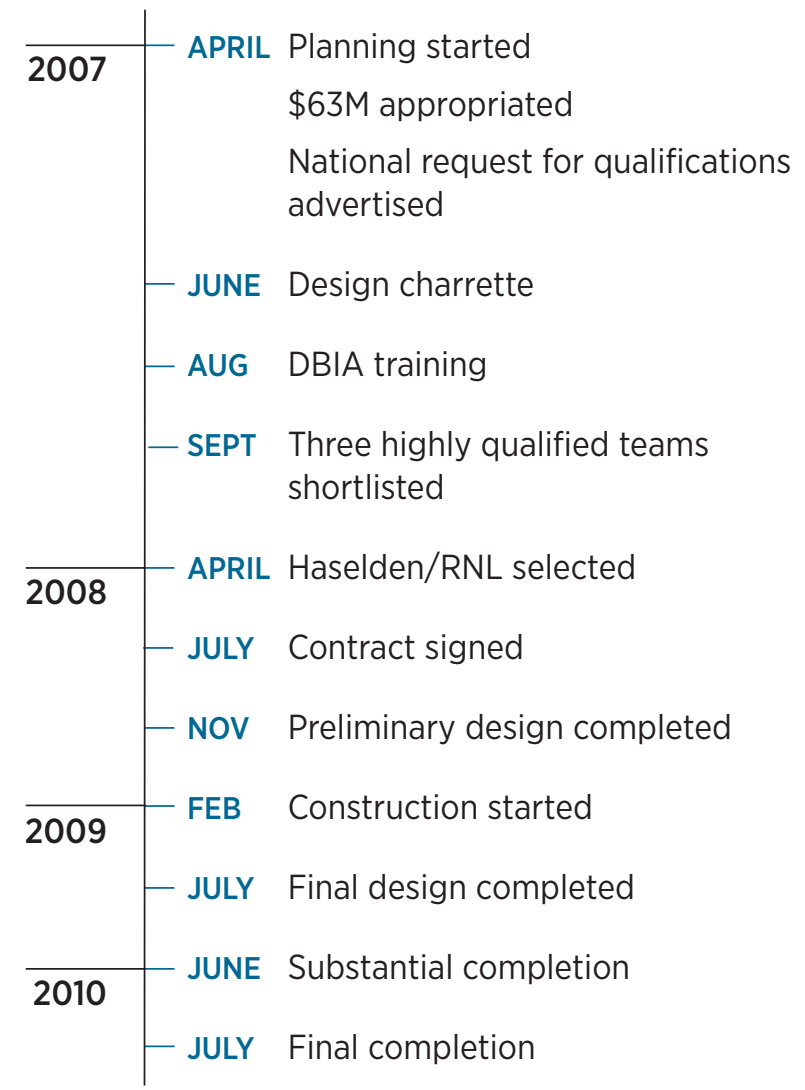




\section{RSF Energy Performance Goals}

Because energy drove the design of the RSF, setting and clearly articulating energy performance goals was a critical component of the design process. In the RSF RFP, the SET specified an energy use intensity (EUI) of $25,000 \mathrm{Btu} / \mathrm{ft}^{2}$ for an approximately $200,000 \mathrm{ft}^{2}$ building with 650 occupants. If the design-builder found ways to fit more people into the building while meeting other performance criteria, then the EUI would increase. With fewer people in a larger building, the EUI would decrease.

DOE/NREL did not want fewer people in a bigger building, so the RFP provided for an EUI adjustment based on a normalized energy use for 650 people and $200,000 \mathrm{ft}^{2}$. The EUI goal was still $25,000 \mathrm{Btu} / \mathrm{ft}^{2}$, but the goal was adjustable for occupancy density.

The DB team eventually fit more occupants - about 822 -into $222,000 \mathrm{ft}^{2}$. The higher occupant density resulted in an adjusted EUI of $31.75 \mathrm{kBtu} / \mathrm{ft}^{2} /$ year. Including an allowance for the data center of 3.35 $\mathrm{kBtu} / \mathrm{ft}^{2}$, the total adjusted energy use goal is 35.1 $\mathrm{kBtu} / \mathrm{ft}^{2} /$ year.

The DB team achieved a higher occupancy density without sacrificing other performance goals, such as providing comfortable workspaces for each occupant.

The RSF EUI goal is very aggressive, and the building is expected to outperform other very energy-efficient, large commercial buildings. Based on actual energy performance data from October 2010- March 2011, the $\mathrm{RSF}$ is operating at an EUI that is $42 \%$ lower than the typical office building.

\section{Developing Building Metrics}

In addition to high-efficiency energy performance goals, NREL commercial buildings research staff used NREL's current plug load profile and density to develop clear, objective, measurable metrics for the details of the building - lighting requirements, comfort at workstations, etc. This exercise was important because as a building becomes more energy-efficient, plug loads account for a higher percentage of total energy use. In a highly energy-efficient building like the RSF, plug and process loads can exceed $50 \%$ of building energy use.

\section{"If you're going to set an energy goal, you'll need help. And you should be setting that energy goal yourself- don't wait for the design-build team to tell you what it is."}

-Nancy Carlisle, NREL Programming and Sustainability Point of Contact

To determine plug loads, NREL researchers conducted an audit of one of the lab's leased office buildings (Building 17 in the Denver West Office Park) and NREL's Thermal Test Facility. Both facilities were

FIGURE 3 RSF Energy Use Intensity (EUI) Comparison
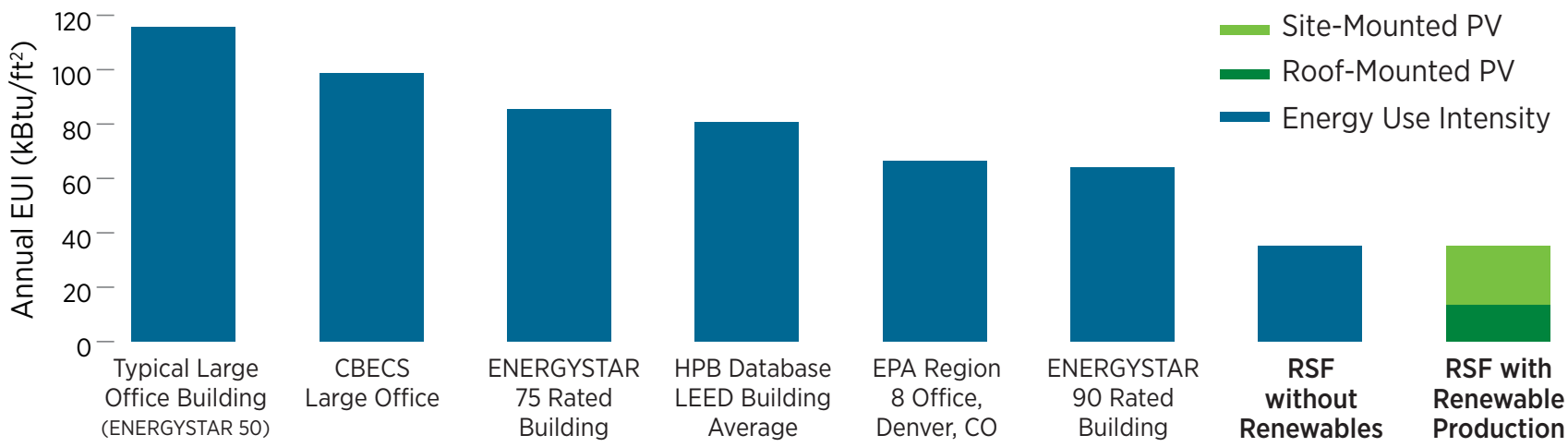

Figure by Stacy Buchanan, NREL 
surveyed first to create an inventory of the office equipment currently in use. Then the equipment was metered to determine an energy consumption baseline. Finally, more efficient options were investigated, such as shifting from CRT monitors and desktop computers to LCD monitors and laptop computers.

\section{Plug Load Reduction Strategies}

\section{Elevators}

- Use energy-efficient elevators

- Change elevator lighting to energy-efficient fluorescent lighting

- Turn off elevator lighting when the elevator is unoccupied

\section{Break Rooms}

- Increase the number of people that use each break room from about 20 to 30

- Eliminate the cooler on the drinking fountain

- Eliminate the use of bottled water by adding filtered water to each sink (and eliminating heating and cooling the bottled water)

\section{Task Lights}

- Shift from 35-watt fluorescent task lights to 6-watt LED task lights

\section{Phones}

- Shift from standard phones to voice-over-internet protocol phones that consume 2 watts each

\section{Copiers, Printers, Fax Machines}

- Decrease the number of people that use individual copiers, printers, and fax machines

- Increase the number of people that use a group's copier, printer, and fax machine

- Increase the use of all-in-one machines (combined copier, printer, and fax)

\section{Computers}

- Increase the number of laptops from 260 (33\% of staff) to 720 ( $90 \%$ of staff).

- Shift from standard 300-watt computers to 30-watt laptops
FIGURE 4 Impact of Reduced Plug Load

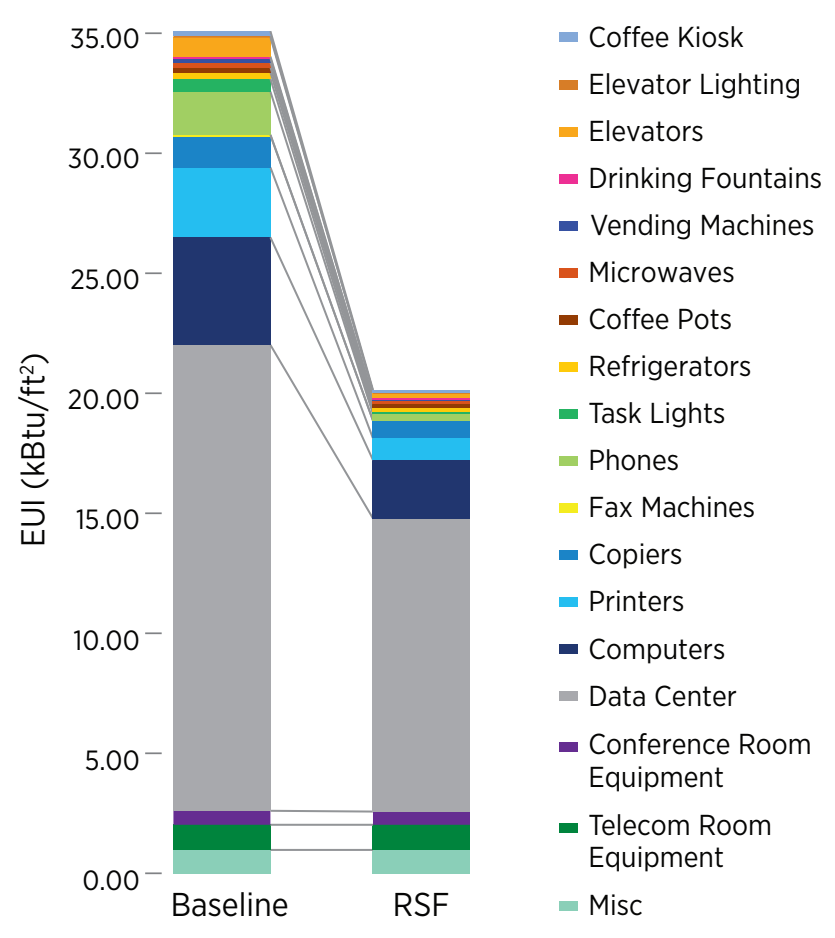

The cumulative result of these strategies was a $31.8 \%$ reduction in plug loads. This reduction does not include additional savings from advanced server technologies, unoccupied hour controls, or higher efficiency kitchen appliances and office equipment. Figure by Stacy Buchanan, NREL

\section{Using Energy Models Throughout Design and Construction}

Another important part of setting energy performance goals for the RSF was modeling the impact of building design decisions on energy use early and often. Having a computer model of the proposed RSF that met performance expectations allowed the team to run simulations during design development and construction to ensure that performance expectations were being met as the design evolved and construction continued.

Energy models can be used to inform the design process and build confidence that the modeled performance is an accurate representation of how the completed building will perform. Models must also be updated to reflect construction changes or installation deficiencies. 


\section{Costs}

For very low-energy buildings to become common practice, the costs to design and build them must be comparable to similar buildings. The costs must also be easily understood by owners and building professionals.

Under the RSF's performance-based DB contract, the design-builder was obligated to deliver a building that met or exceeded the owner's stated performance goals for a firm fixed price. RSF construction costs were \$57.4 million, and the final DB contract for the completed RSF was $\$ 64.3$ million, not including infrastructure, landscaping, parking, or photovoltaics (PV). The finished building is approximately $222,000 \mathrm{ft}^{2}$, for a construction cost of $\$ 259$ per square foot, and a final cost, including furnishings, of $\$ 288$ per square foot.

The RSF's cost is comparable to similar buildings along the Front Range of Colorado.

Although high-performance buildings like these can be built with budgets comparable to similar buildings, the costs of various parts of the DB process are different. As Figure 6 illustrates, architectural costs are typically higher, while mechanical costs are lower in a highperformance building.

The RSF is expected to significantly reduce DOE's energy costs. Also, because the employees housed in the RSF were moved from leased space, based on lease costs of \$5.5 million annually (in '07 dollars), the savings over 20 years from lease costs alone have been conservatively estimated at $\$ 122$ million. The money saved can be applied to NREL research and development rather than rent.

\section{FIGURE 6 Cost Transfer}

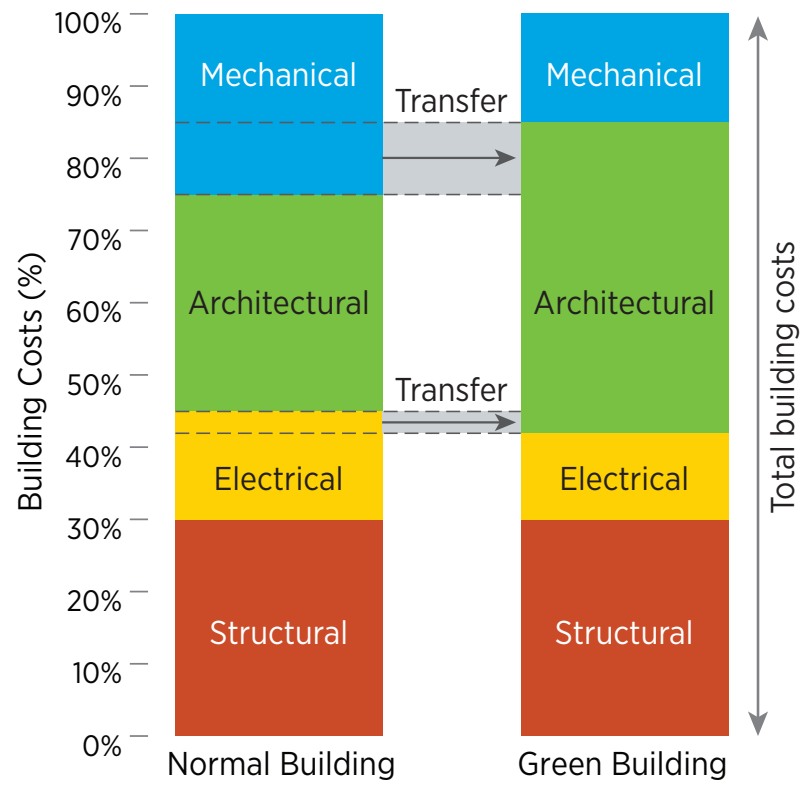

Figure by Stacy Buchanan, NREL

\section{FIGURE 5 Commercial Construction Building Costs - By Cost Per Square Foot}

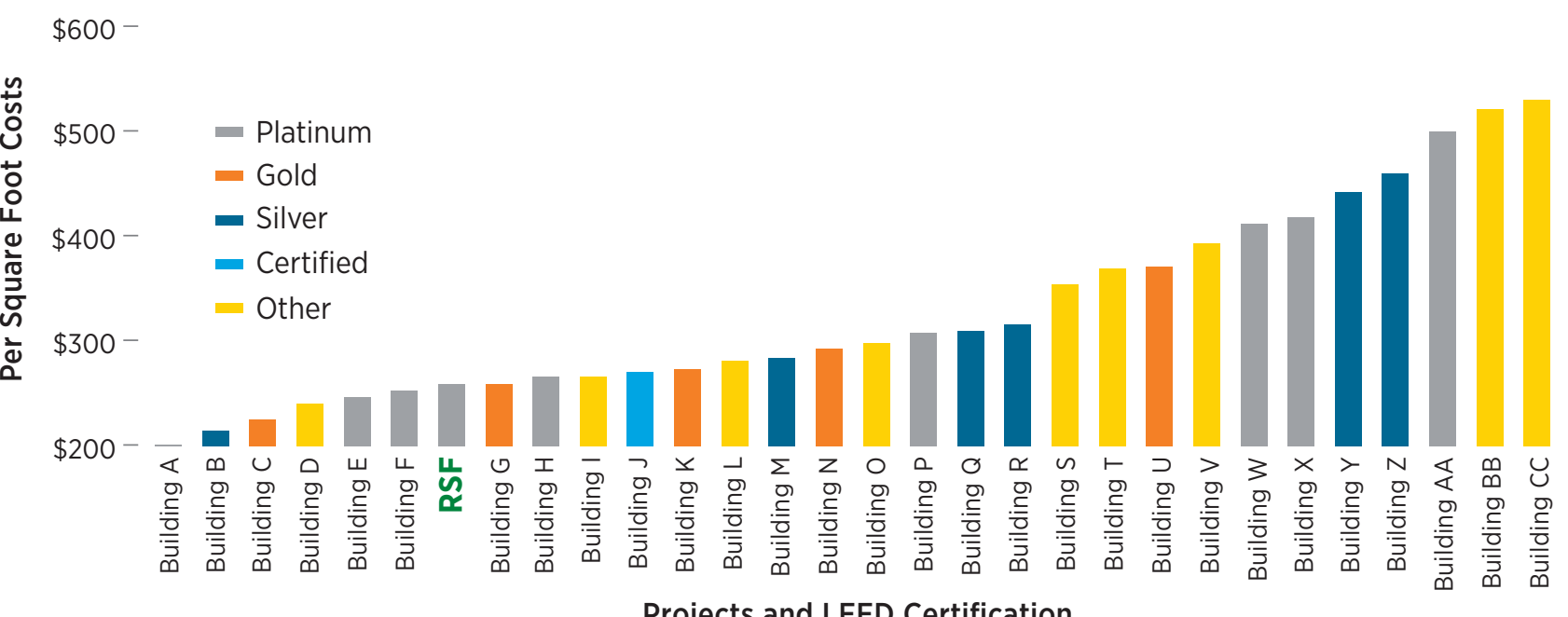




\section{Why Performance- Based Design-Build Works}

The benefits of DB delivery have been apparent for some time. Back in 1997, a Penn State researcher compared the DB and design-bid-build project delivery methods (Konchar, 1997). He found that DB projects cost an average of $6 \%$ less, were an average of $12 \%$ faster to build, and were an average of $33 \%$ faster to deliver (i.e., from conception through completion).

Especially for an innovative building, DB delivery coupled with clear and prioritized performance requirements (performance-based DB) appears to be a winning combination. And establishing prioritized performance goals from the beginning greatly increase the probability that the completed building will meet the project's critical goals. As the RSF process demonstrates, when the owner's RFP clearly calls for a net-zero energy building, all the players consider design strategies based on how they affect that outcome.

\section{"We had to be careful not to violate the spirit of the DB contract, which says more or less-once the specifications are set-to let the design-build team do their work in their own way." -Ron Judkoff, NREL Buildings Program Manager}

\section{Encourages Innovation}

In performance-based DB, the design-builder is responsible for designing and constructing a building that meets the owner's stated performance goals. Because the design-builder knows the relative priority of those goals from the beginning and controls the design and construction of the building, all possible paths to netzero energy are available.

This scenario places the responsibility for innovative solutions where it belongs - on the participants schooled and experienced in design and construction - rather than on the owner. In addition, when collaborative and trusting relationships develop among team members and everyone is working at their best, the result is superior performance.

\section{Reduces Owner's Risk}

In a performance-based DB procurement process, the owner is extensively involved in setting the performance goals documented in the RFP. Once the design-builder has assumed contractual responsibility for achieving the performance goals, the owner's risk is dramatically reduced compared with a design-bid-build scenario.

In a design-bid-build scenario, the onus is on the designer to identify and communicate the owner's requirements to the builder. Those mandated and inflexible requirements are documented in the plans and specifications for the building. But no set of drawings is perfect, and it often happens that when the contractor is retained and construction begins, imperfections begin to emerge.

In their agreement, the owner has warranted to the contractor that the plans and specs are complete and correct, and the contractor has agreed to construct the building based on those documents. The contractor wants the owner to be happy with the building, but can't afford to pay for time, materials, and/or equipment that weren't specified correctly in the construction documents. The result is that the contractor presents the owner with change orders to bridge the gap between the building as originally designed and the building as constructed, and the cost of the project increases.

On design-bid-build projects, change orders and cost overruns are commonplace. Litigation is much more common in a design-bid-build scenario.

On performance-based DB projects, the owner develops performance specifications that describe what the building should do. The design-builder comes up with the solutions required to deliver a building with those characteristics. When something does not perform as planned - the HVAC doesn't perform as expected, for example - the design-builder is responsible for repairing or replacing it at no cost to owner.

Although many agencies and large owners are reluctant to give control to a design-builder, DB is clearly a good deal for an owner. In design-bid-build, the designer and 


\section{"Every one of these strategies is very replicable, and many of them are appropriate for all buildings and all locations."}

contractor often develop an adversarial relationship and the owner is caught in the middle. In DB, they are motivated to develop collaborative decision-making processes because they succeed or fail as a single legal entity. In this situation, differences of opinion about scope, schedule, or budget are no longer the owner's problem.

\section{Faster Construction and Delivery}

Because DB does not require a lengthy bidding process before the building contractor joins the team, it is the fastest project delivery method and saves the owner the effort to issue a separate RFP for construction. For example, site work on the RSF began in February 2009 while the DB team was still developing the final design. The drawings were completed in August 2009. If the RSF had been a design-bid-build project, it would likely have taken a month or so to get the bids back, and then another month or two for NREL to award the contract. Instead of starting in February, the project probably wouldn't have begun before October 2009. Clearly, DOE/NREL saved time and effort with DB delivery. Beginning construction sooner and allowing design and construction to progress in tandem, can also mean lower costs and better cost control, especially on projects that are complex or financed with construction loans.

\section{Better Cost Control}

Because the budget is determined and verified early in the process and the design develops within the owner's financial constraints, there are fewer opportunities for cost overruns. When costs do exceed the budget, it is the design-builder's - not the owner's - responsibility to adjust the solution. In addition, the design-builder is contractually bound to control costs without sacrificing any of the performance measures documented in the RFP. The owner is guaranteed a building that meets the requirements of the RFP, on time and within budget.

\section{Makes Optimal Use of Team Members' Expertise}

Performance-based DB takes advantage of the knowledge and skills of all the construction professionals involved in the project from early in the process. An added advantage is that members become familiar and comfortable with each other long before construction begins. Because the general contractor-typically the team member most familiar with cost and constructability issues - has input during the design process, this delivery method takes full advantage of the contractor's experience and knowledge.

Equally important, all key stakeholders - especially the contractor - should be in agreement with the design concepts. Detractors who show up late can really derail an integrated approach to delivery.

\section{Establishes Measurable Success Criteria}

As the saying goes, what gets measured gets managed. A performance-based RFP focuses on measurable performance criteria rather than prescriptive solutions to design problems. It describes how the building will perform, in clear, measurable terms - what the building will do rather than what it will be. This frees the owner to concentrate on the functional expectations of the building rather than worrying about the details of how to meet those expectations, and allows the design-builder to draw from all possible solutions rather than only those prescribed by the plans and specifications. The more clear and measurable the performance criteria are, the more likely the project will successfully meet them. 
"The owner has to commit to goals early on and not change their mind."

- Paul Torcellini, NREL Commercial Buildings Research Group Manager

\section{Keys to Success}

The process of designing and constructing ultra energyefficient buildings is evolving, but a few strategies have emerged that improve the chances of success. These strategies are based on DB experiences with low-energy buildings in general, and with the RSF in particular.

\section{Educating the Team}

A well informed team is a more effective team. Before beginning the performance-based DB acquisition of the RSF, NREL staff completed owner-specific education offered by the DBIA. The entire ownership team learned about performance-based DB best practices, market trends, and management techniques. This targeted education allowed DOE/NREL to make thoughtful and timely decisions, and provided a level of confidence in dealing with the paradigm shift associated with DB procurement.

As one DB veteran points out, "Despite the stories of success by others, owners should never jump into an acquisition process without support via education, technical assistance, or both. When we know better, we do better, but we always do what we know."

\section{Clear, Comprehensive RFP}

Writing an RFP for a net-zero energy building can be daunting for a building owner. Because making the RFP as clear and comprehensive as possible is key to the project's success, many experts suggest hiring a specialist to help.

The RFP must be carefully thought out, tested for achievability, and clearly written. Because RFPs for commercial buildings are typically hundreds of pages long, it must also be well-organized and easy to navigate.
Even seasoned construction professionals with DB experience don't always use consistent terminology to describe procurement methods, pay methods, etc., which can lead to confusion. Including definitions in the text or in a glossary can help avoid miscommunications.

Describing performance objectives in clear, specific, measurable terms in the RFP greatly improves the probability of achieving them. In addition, performance expectations must include metrics to gauge success.

\section{Prioritized Scope}

Prioritizing a project's scope ensures that the owner receives proposed solutions that fit within the budget. This prioritization ranks the owner's needs in at least three areas - mission critical (must be provided), highly desirable (should be provided), and if possible (optional). Performance-based DB gives the designbuilder control of the solution and prioritizing the scope helps ensure budget compliance by the design-builder. As the design-builder considers various solutions to the RFP, focusing on high priority requirements - even at the expense of low priority options - is an effective strategy for aligning the solution with the project's budget.

\section{Award Fee}

The Award Fee Incentive Program was instrumental in giving DOE/NREL a strong voice in the contract and keeping the design-builder motivated to perform superior work and to stay fully engaged in the process. Money drives behavior, and DOE/NREL was willing to pay for superior performance.

\section{"The award fee balanced the team into not only wanting to work on the project and with NREL, but also gave us the desire to perform the best at the highest level."}




\section{"The award fee program gave NREL a tool to motivate the contractor. It ensured that NREL had input. We had a voice-and they were motivated to listen."}

\section{Selecting a Design-Builder}

In addition to writing a detailed RFP for the building, it is critical that the owner selects an experienced, committed design-builder. The process of selecting a design-builder involves:

- Preparing a solicitation for services

- Requiring requests for qualifications (RFQ) from prospective teams

- Evaluating RFQs

- Developing a short list of teams

- Evaluating the RFP proposals

- Interviewing the short-listed teams

- Preparing a final ranking of the teams

- Negotiating with the highest ranked team.

Meaningful financial incentives - both for the finalists in the hiring process and for the successful firm throughout the project - are effective tools for supporting positive outcomes. For the finalists, preparing a proposal for a performance-based $\mathrm{DB}$ project requires a significant investment of time and resources. DB consultants generally suggest that the owner offer a stipend of $50 \%$ of the expenses incurred.

\section{Communication}

A successful, sustainable building that generates as much energy as it uses requires more than top-notch technical, design, and construction talent. It also requires the personal commitment of everyone involved in both the process and the outcome. As one participant puts it, "Individuals make this stuff happen, not companies."

For building professionals new to performance-based $\mathrm{DB}$, adopting this delivery method requires changes in both individual and organizational behavior. For some, these changes can be painful and difficult, but one DB expert asserts that, "People and organizations grow and evolve as a result of this process. It changes people for the better."
Many project details are determined through negotiations among the owner, design-builder, and other team members, making the quality and frequency of communication critical. As members of the RSF DB team noted, the three most important tools for success are: communication, communication, and communication.

On the RSF, for example, most team members are on site daily and attend formal weekly project meetings. Although good designers and builders solicit input from owners regardless of the project delivery method, RSF team members report that the quality of communication among team members is exceptional. According to one participant, "Every individual on the team really has a sense of belonging and ownership. On a design-bid-build job, if there's a mistake we pay the emotional and financial price. In DB, we're working as a team —we pick each other up."

Especially on a net-zero energy project, good communication must extend to subcontractors and their employees. On the RSF, project level people meet with subcontractor foremen weekly. Those meetings are an opportunity to communicate both cultural values (such as safety and energy efficiency) and the details required to successfully deliver a highly energy-efficient building.

"It's important to get the operational side of the building integrated with the design and construction side. Transparency and communication are critical through the entire process." 


\section{Get the Details Right}

The result of all the effort going into the RSF performance-based DB is apparent throughout the jobsite. During a conversation with a worker who was installing insulation in headers at the RSF, the worker explained that it was important that he do it carefully because it would affect the energy efficiency of the building, and that it was "really important to the owner." The probability of success increases dramatically when the trades people on the job are invested in creating an energy-efficient building.

Getting installation details right helps ensure that as-installed performance matches the energy models and the owner's performance goals. These details are verified through a substantiation process that should be part of the DB team's agreement with the owner.

In the case of the RSF, NREL required detailed verification and monitoring of the building during and after construction. For example, significant design and coordination time was spent determining best PV roof-mounting strategy, because the power purchase agreement provider - who is not a party to the DB agreement-wanted to attach the PV arrays using 600 steel posts that would penetrate through the roof insulation. The architect and builder devised a mounting strategy that minimizes thermal breaks to ensure that the energy goal was met and the roof insulation $\mathrm{R}$-value in the energy model wasn't compromised. 


\section{Design-Build Process Challenges}

For many building owners and professionals, performance-based DB is a new and intimidating prospect. The construction industry is notoriously conservative, and it takes time and repeated exposure for building professionals to embrace new concepts and strategies.

Owners and designers are in the habit of developing detailed prescriptions for contractors to follow. Convincing owners that they can get a better building in less time for a firm price by releasing control of the design and construction to a design-builder is still a hard sell in most cases.

The need to reduce the environmental impact of buildings - particularly the impact of energy use - is driving an industry-wide trend toward "greener" buildings. Although the idea of more energy-efficient, healthier buildings is emotionally and intuitively appealing, the reality of designing and constructing such a structure can be daunting. For example, writing an effective RFP for a large commercial building is overwhelming to most building owners.

\section{"The owner needed to understand how this process differs from other construction projects. When the owner and the design-builder became a fully integrated team, trust and mutual respect happened."}

- Leandra Thompson, Owners Representative, Northstar Project Management, Inc.

DOE/NREL had an advantage in that they have engineers and researchers on staff who have technical expertise and personal and professional commitment to write performance criteria likely to result in a positive outcome. The RSF RFP can serve as a guide for owners willing to take on the challenge, but some DB veterans suggest hiring an expert to assist with RFP preparation. According to the DBIA, finding and vetting such a firm is getting easier, but for most building owners, the DB approach is a leap into unfamiliar territory.

Assembling a group of professionals with the right skill sets and temperaments to form a cohesive team is also a challenge. To be successful, team members must develop trusting and collaborative relationships. To get to the most innovative solutions, participants have to feel safe enough to make suggestions and make mistakes.

\section{Commissioning Challenges}

The IPT experienced some challenges about how to integrate the commissioning statement of work into the DB delivery method. Defining commissioning roles and responsibilities and scope of work for the designbuilder, the owner's representative, and any thirdparty commissioning agent is necessary early on.

Building owners should be clear about any commissioning requirements desired by an organization that are above and beyond the LEED commissioning pre-requisite or credit criteria and include these in the RFP.

Including commissioning substantiation criteria in the RFP would have allowed a clear understanding of expectations up front and would have prompted an early discussion and agreement on the best process.

The latest version of LEED requires the owner to hire their own commissioning agent.

Organizations have to commit their best and brightest to the process. The DB team is accountable for delivering the project on time and on budget, and there is no room for sloppy work or procedures. Each participant has to be both a leader and a collaborator.

Performance-based DB done correctly can be challenging, but it will get easier as it becomes more common and building professionals become more comfortable with it. Its advantages as an effective delivery method for innovative buildings make the learning process worth the effort. 


\section{Safety: The Top Priority}

At NREL, providing a safe and secure workplace is the top priority, which includes on-site temporary construction workers. The very first mission-critical objective for the RSF was "Attain Safe Work Performance/Safe Design Practices."

NREL's construction safety point of contact met with the DB team early on to make sure they understood DOE's 10 CFR 851 — worker safety and health regulations that govern contractor activities at DOE sites. NREL had an occupational physician and clinic, as well as a fit-for-duty program. Identifying all preexisting conditions saved time and injury rates along the way.

Three activities helped ensure a safe job site and provided a good initial structure for the RSF construction:

1 Initial meetings were held prior to all phases of construction.

2 NREL worked with Haselden to develop safety training for all workers. NREL's 20-minute portion of the orientation included environmental stewardship and DOE/NREL site security, enhancing Haselden's existing orientation.

3 Haselden conducted criminal background checks on all of their workers.

\section{NREL's Safety Successes}

The DB team completed the following tasks to help ensure a safe working environment.

\section{Weekly Safety Walks}

Soon after the initial three-day kickoff meeting with all partners, NREL began conducting weekly meetings for NREL, DOE, Haselden, RNL, and Northstar Project Management to go over all activities for the week, along with future scheduled activities. Discussing safety - including the results from the same day's safety walk-through-became the top item on the IPT's meeting agenda each and every week for several years. A critical element of the safety walkthroughs included interviewing workers on the jobsite to see if the safety culture reflected DOE/NREL values.

\section{Documenting Safety}

Including safety language in contracts is one thing. Ensuring safety is another. Daily safety logs were kept, and up to 150 pages of safety documentation were submitted each week during RSF construction.

\section{Hazard Activity Analysis}

For all definable features on the project, NREL met with Haselden and its subcontractors to talk about their processes and conduct a Hazard Activity Analysis (HAA) prior to beginning any new work activity (i.e., crane work). Any subcontractor that put any equipment and materials in the RSF was required to have an HAA. This is one way that NREL demonstrated to DOE that there was adequate oversight on the project.

\section{Safety Rating System}

NREL created a safety rating system for the project that helped determine the DB team's award fee each month. NREL's continuous feedback on safety was a structured, measureable element of the award fee.

- Superior - Perfect safety record: no safety issues found.

- Excellent - Minor issues found that could result in safety hazards.

- Satisfactory - Issues found that need to be corrected.

Haselden maintained an outstanding safety record throughout the RSF project, and they received 12 Superior ratings during the course of the project. Their 0.49 experience modification rating proved that the partnership between DOE/NREL and the DB team worked in relation to safety.

\section{"We have built an environment of camaraderie and respect when it comes to safety." \\ - Shawn Bradfield, NREL Construction Safety Point of Contact}




\section{Rapport with DB Team and Subcontractors}

NREL and DOE made a conscious effort to communicate with workers on the jobsite. Far from silent partners, DOE and NREL were active participants in ensuring construction safety. Through a positive rapport and mutual understanding of the safety culture at NREL and DOE, numerous issues were resolved quickly.

\section{Safety Challenges}

While the RFP contained a list of DOE safety codes, code interpretations were sometimes challenging. For example, there was a fire protection issue that involved the beetle kill pine used in the RSF lobby. Code experts were hired, and the DB team worked closely with NREL to resolve the conflicts surrounding the code interpretation. 


\section{Security: Fulfilling DOE's Requirements}

DOE's Physical Protection Manual 470.4-2 establishes requirements for the physical protection of interests under the DOE's purview. While DOE/NREL included reference to DOE Manual 470.4-2 in the RFP, the DB team had a different interpretation of the security requirements for DOE buildings, so detailed considerations for security were not included in the initial building design. NREL Security and the DB team interpreted the RFP differently, which led to conflicts regarding security requirements for the building.

\section{Operable Windows Required} DOE Variance to Meet Security Requirements

Per the RFP, the DB team was required to provide natural ventilation in the facility. Because the building's design and energy model's success relied upon using operable windows for natural ventilation, the DB team's research and support led to NREL and DOE obtaining a variance to DOE 470.4-2, Physical Protection.

\section{Energy Model Impacts Security Requirements}

The RFP document and the DB team's energy model drove all decisions about the RSF. This was a challenge for NREL's Security team because as the building design evolved, security requirements had to be reevaluated. Securing the interior of the building became an issue because many secure rooms have open ceilings to allow for daylighting.

\section{Security Costs Higher than} Anticipated

According to current best practice in government building construction, at least $5 \%$ of the total design and construction cost is allocated to security. Campus-wide security requirements changed during construction of the RSF, which resulted in more security requirements and costs for the RSF.

\section{Security Challenges}

For all future DB RFPs, NREL will provide a security narrative document that contains security requirements that must be taken into account. Equipment such as card readers, door position switches, back-up power, system security, duress/panic buttons, intercoms, remote surveillance systems, door hardware, public address system, in-building amplification, emergency telephones, and automated external defibrillators should be included and planned for in the overall budget. 


\section{Quality}

The IPT's commitment to quality was important to the success of the RSF. NREL took a proactive approach to reviewing Haselden's construction work prior to finalization. Four months into the construction process, NREL and Haselden began conducting weekly quality walks on the construction site, and findings were reported in subsequent IPT meetings. In addition to the quality walks, verifying supporting documentation for all materials proved to be very useful.

Trust and transparency were critical to the quality process. Over time, Haselden would self-disclose issues to the IPT if they found something that needed to be examined further. While NREL had a quality assurance specialist consulting with the IPT, Haselden also had a quality counterpart working closely with NREL on purchasing decisions for materials.

As a government entity, DOE is required to adhere to the Buy America Act, meaning that products had to be purchased in the United States. The DB team was familiar with the Act, but their awareness increased substantially during construction. At pre-construction meetings, quality was always an agenda item, and it remained on the agenda during weekly meetings throughout the project.

"Our weekly quality walks were like mini audits, and we included our subcontractors. We were able to catch things early on, and we didn't wait too long to resolve issues."

- Allan Roberts, NREL Quality Assurance Specialist 


\section{Using Photovoltaics and a Power Purchase Agreement}

In the design process of the RSF, it was clear from early on to the DB team that achieving a zero-energy approach to the project held the key to aligning cost control with leading edge energy performance.

One of the "if possible" goals on the project objectives checklist was to use a net-zero energy design approach, meaning that the building should be designed to minimize the energy consumption and then use PV (or other building integrated technology) to offset those energy requirements. PV panels are, for most contemporary construction projects, enticing but not affordable, with costs of $\$ 5-6 / \mathrm{ft}^{2}$ for large scale projects, including tax incentives. For the $222,000 \mathrm{ft}^{2} \mathrm{RSF}$, that could amount to nearly $\$ 250,000$. The DB team had to find a way to deliver PV, but reduce start up costs.

\section{Overview of a PPA}

A power purchase agreement (PPA) is a three-party contract between a building owner (DOE), a solar power developer (Sun Edison), and a utility company (Xcel Energy). This form of agreement is often used in commercial building operations to address situations where the upfront cost of replacing, adding, or upgrading a major building system (i.e., central plant or geothermal installations) would exceed the available capital. In this scenario, the owner dedicates operational funding over an extended period, once the system is in place.
As is the case of many energy efficiency options, including PV systems, the initial costs can be offset in two ways: 1) ongoing electrical power purchase, or 2) government tax credit for the investment. As a federal agency, DOE is not entitled to a tax credit, but a third party solar power developer can access tax benefits and earn tax-sheltered profits for the term of the contract (typically 20 years).

\section{DOE and NREL Experience with PPAs}

Both DOE and NREL have extensive experience procuring large PV systems using PPAs at NREL's STM campus. Within Colorado, the distribution of Renewable Energy Credits (RECs) is managed by the statewide utility company, Xcel Energy. By law, 30\% of Xcel's generating capacity must be from renewable sources by 2020, and it is permitted to sell RECs to solar power developers. They then annually release RECs to selected proposals for various sized arrays located within the state.

There are currently two arrays on the NREL campus: one on the mesa top, sized at $720 \mathrm{~kW}$, and another on the roof of the Science and Technology Facility, sized at $94 \mathrm{~kW}$. In addition to these two PPAs, there is another that supports and operates NREL's Renewable Fuels Heating Plant, home of the campus wood chip boiler.

DOE-GO manages and operates the PPAs and has been instrumental in successfully procuring the arrays already in place. The contracts are competed and managed by the Contracting Office and the senior contracting officer.

\section{TABLE 3 Benefits of Using a PPA}

\begin{tabular}{|l|l|l|}
\hline \multicolumn{1}{|c|}{ Building Owner } & Solar Power Developer & \multicolumn{1}{c|}{ Utility Company } \\
\hline - Receives clean, renewable energy & - Receives 30\% Federal tax credit & - Can claim renewable energy \\
- Receives a competitive long term & - Receives Solar Renewable Energy & toward required renewable \\
power cost control through the & Credits (RECS) from Utility & portfolio \\
$\begin{array}{l}\text { contract } \\
\text { - Provides roof or site area for PV }\end{array}$ & - Receives 20-year contract for power & - Provides annual net metering \\
\hline
\end{tabular}




\section{Project Approach to PPAs}

One of the overarching lessons of the project has been the deeply integrated nature of design and construction of an ultra energy-efficient building that produces as much energy as is consumed. What the team experienced was that every major, and some minor, design or construction decisions have an energy 'cost.' This was definitely the case for PV system design.

Creating a highly efficient building that can also produce power from $\mathrm{PV}$ is a balance of building volume (number of floors), compared to available roof area, and the design energy demand. Too compact of a building configuration would not allow enough roof area to generate power, and too much energy consumption would exceed the energy output of current panels.

In the initial approach, the DB team considered not only roof-mounted PV but also façade (or vertically mounted) PV. This approach, when combined with a full rooftop array, allowed enough power to be generated within the building footprint. However, these types of panels are low energy providers and not cost effective. The final design included PV systems on an adjacent parking lot and future parking structure for a total electrical output of 1.6 MW.

\section{Special Focus Team}

With an early focus on using renewable energy to offset energy demand, the DB team included a group of design professionals that collectively could provide expertise around four key energy design areas: energy modeling, daylight modeling, PV design, and architectural design. With a fixed price contract, those four energy areas had to be balanced with the cost model when making design choices.

Responsibility was assigned as follows:

- Stantec Consulting, one of America's largest sustainably focused engineering firms, provided MEP engineering and energy consulting. With extensive experience in this area, Stantec was able to establish key building guidelines, including the radiant slab technology approach for overall building conditioning - pieces of the puzzle that are the foundation of the RSF's low energy performance.
- Daylight modeling was delivered by Architectural Energy Corporation. With thorough understanding of daylight and climate, the team established very low window-to-wall ratios, limiting overheating associated with too much glass, and providing important cost control to an otherwise very expensive glazing system.

- Namaste' Solar Power brought expertise in solar systems considerations, and assisted in defining the best integrated approach to solving the energy challenges.

- RNL provided long-standing expertise in designing complex buildings using a collaborative approach that made low energy performance the key outcome. RNL's architectural approach integrated all the necessary energy saving and generating systems into an aesthetically pleasing building.

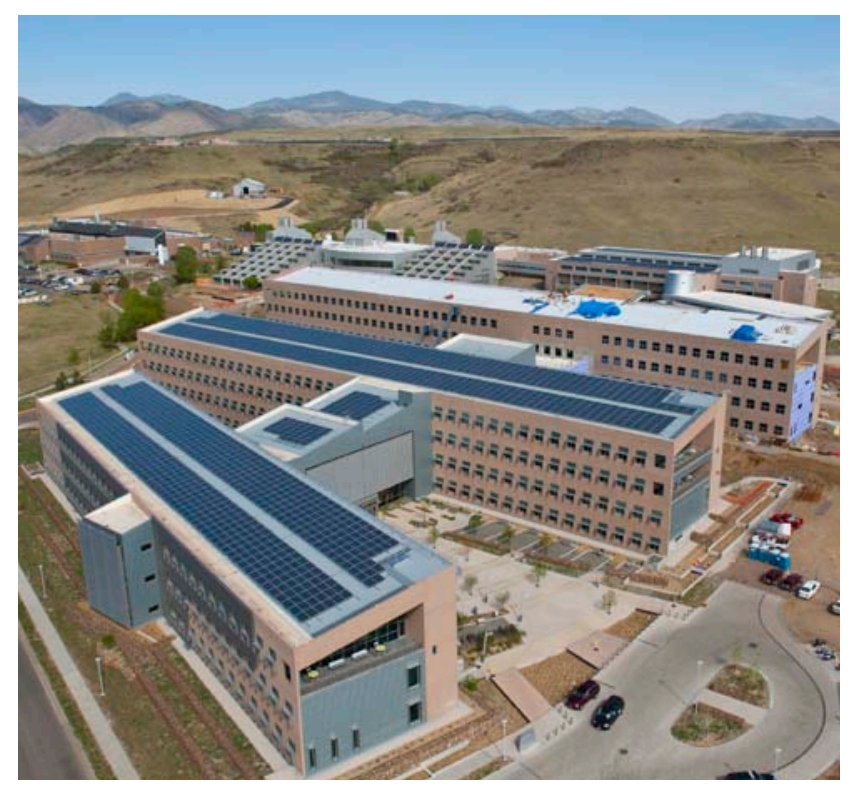

The RSF includes $450 \mathrm{~kW}$ of roof-mounted PV panels. Photo by Dennis Schroeder, NREL/PIX 19089 


\section{PPA Lessons Learned}

Several key lessons were learned during the PPA process:

- Integrating building form and cost control in a low-energy building design is arguably the first step; therefore, an integrated process must begin with the first steps in the design process. A DB delivery process is a very powerful tool for owners to use to align cost control and low energy performance.

- PV is often an after-market technology, applied to existing buildings, and the current market experience with building integrated PV on new construction is very limited. Collaboration and an integrated process within the project's design schedule should be a contract requirement of the solar power developer.

- Thermal bridging is the enemy of low-energy design, acting like a leaking roof in a rain storm. It can allow substantial energy (cold transfer in winter, hot transfer in summer) to leak out, increasing energy use, and defeating an otherwise good building envelope. Thermal bridging is poorly understood by the current field of solar power developers and managing this important performance measure should be integrated into future contracts.

- Well-developed RFPs are essential to achieving any goal. In the case of the RSF, the clearly stated energy goal and the "stretch" goal of net-zero were essential to directing the process. 


\section{Getting Employees Ready to Move to the "Workplace of the Future"}

Two years before the RSF was scheduled for completion, the DB team encouraged NREL to begin "socializing" the RSF building design with their employees. Working in open office environment with extensive daylighting and low cubicle walls, combined with the shift to ultra-high efficiency computers, multi-function printers, and voice over IP phones meant that staff would need to shift their conceptions about their workplace well before moving into the RSF. Employees also needed to learn how to modify their workplace habits, help reduce their energy consumption, and interact with the building to help it use as little energy as possible.

\section{"You can design and build a very efficient building, but what you need are all of the occupants in the building to make that same commitment."}

- Wendy Weiskopf, Interiors Manager, RNL

\section{Prototyping the Workplace of the Future}

With growing national emphasis on renewable energy and energy efficiency, NREL and DOE began to experience an increase in hiring beginning in 2007. While this was good news, it also meant that additional office space needed to be leased to accommodate the growth. Less than a mile from NREL and DOE's main administrative buildings, space was available in the Golden Hill LEED $^{\circledR}$-certified building.

RNL worked closely with the IPT to purchase and install the same type of modular workstations in Golden Hill that were also being planned for the RSF. In November 2008, nearly 100 NREL information technology staff moved into the new building and were the first to try out the "workplace of the future," featuring increased daylighting, lower cubicle wall heights, and the use of highly energy-efficient technology.

Managers and employees from throughout NREL and DOE had the chance to tour Golden Hill during 2009 and 2010 to help as many staff as possible visualize what it would be like in the RSF. Giving staff adequate time to learn how their new workplace would be different than what they currently had would be critical to the change management process.

\section{Communication Tools}

NREL's communications team developed many face-to-face and electronic communication tools to help familiarize its employees with the new building, offer numerous opportunities for dialogue, and answer their questions. Making sure hundreds of workers had timely access to information, delivered via numerous channels, was critical.

\section{Internal Web Page}

Beginning in 2009, a shared extranet Web page was published for both NREL and DOE staff to access information about the building that was relevant to staff. After DOE decided that the building occupants would be from NREL, the page moved internally. Topics included computers, conference rooms, daylighting, huddle rooms, privacy, sound control, and workstation layouts.

\section{Newsletter Articles}

Communications staff began writing articles about the RSF in 2007, when funding was initially approved. From 2007 through June 2010, writers published numerous stories about the building, including construction photos.

\section{Brown Bag Lunch Series}

A series of lunch time presentations were offered to staff to help them learn more about the building itself; the new technology that everyone would be using; highlights of the move process; and staying healthy, safe, and secure in the RSF. 
"This is a very significant change in the work environment, and it has some very significant cultural impacts. We have a multigenerational workforce and different levels of acceptance of this new type of work environment."

\section{- Bill Glover, NREL Deputy Director}

\section{Online Feature Stories}

NREL's public website includes weekly home page feature stories about research, development, and deployment of various technologies and programs. NREL published 10 stories about the RSF to help various audiences — including staff — learn about the building's numerous energy efficiency and sustainable features.

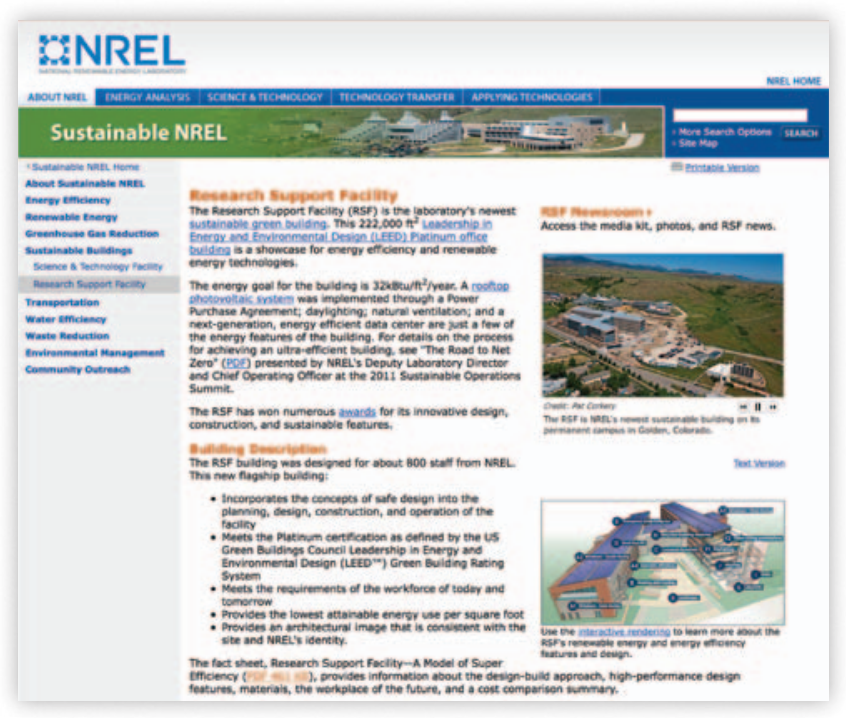

NREL's RSF website www.nrel.gov/rsf includes links to the Request for Proposal, NREL's commercial buildings research publications, photos, and feature stories about the building's construction.

\section{RSF Email Box}

NREL also set up a separate email address so employees could submit questions about the building or the moves whenever they wanted. Questions were then forwarded to subject matter experts who responded quickly to questions or concerns.

\section{Workstation Demo}

Each spring, NREL hosts a lab-wide awards ceremony to recognize outstanding employee performance and an employee "expo" with exhibits. RNL set up a typical 72 square-foot work station identical to that used in the RSF. Staff could see the office prototype and help them visualize their workplace of the future.

\section{Manager Training}

With about 800 staff moving to a new office environment, it was critical that managers understood and embraced the changes that everyone would experience. Change management became a strategic component to the communications strategy. NREL managers attended several meetings to understand how to effectively address the changing work environment.

\section{Move Meetings}

One month prior to when an organization was scheduled to move, employees attended an "all-hands" meeting to discuss move logistics, employee health and safety, building security and badging, and information technology. Staff asked subject matter experts questions and experienced a feeling of anticipation and increasing excitement about the RSF. While there still was not 100\% acceptance of the new work environment, staff had ample opportunity to familiarize themselves with the building features.

\section{Staff Open House}

Less than two weeks after DOE/NREL received occupancy of the RSF, all NREL and DOE staff were invited to attend an RSF Open House where they were able to tour the building and learn about the important building features that help it perform as a highly efficient and sustainable building.

\section{E-Learning Training Module}

NREL created an internal training module to orient new staff to the RSF. Because employees moved in waves, the training module provided online access to RSF information at any time.

\section{Videos}

NREL produced two videos about the RSF to help educate employees and the public. View the RSF video on NREL's YouTube channel at www.youtube.com/nre/pr.

\section{Tours}

Employees were encouraged to familiarize themselves with the building features and new workspaces by touring the RSF prior to their move. 


\section{RSF Building Systems Performance To Date}

While $450 \mathrm{~kW}$ of PV power have been fully installed on the RSF roof and are partially offsetting energy requirements for the building, additional PV panels have also been installed on a visitor parking lot and more will be added to a nearby parking garage.

On June 23, 2011, the RSF had its first day of net-zero energy. When all the PV is installed, the RSF energy model and current building energy data predict that the PV power will completely offset energy use.

\section{"The solution is simple, honest, and elegant. There is tremendous beauty in reaching zero."}

- Craig Randock, Design Principal, RNL
NREL's commercial buildings research engineers are continually monitoring the building's performance and learning from the results. These engineers are using the RSF energy model that was originally developed by the DB team to guide the building's operations. The ability to check performance relative to the energy model is a great training resource for operations staff and a great supplement to commissioning work.

\section{Plug Loads: Planned vs. Reality}

Engineers are continuing to learn about the impact of building operations on plug loads.

First, daytime plug loads are lower than were predicted in the energy model. Only about $75 \%$ of occupants who have moved in are actually at their desks working on any given day. Staff may be on travel, in meetings at different NREL locations, or telecommuting from home.

Second, nighttime plug loads are still difficult to manage. Some programmable outlets have been added after the building was completed to ensure that power is not used when not needed. Laptops apparently do not necessarily sleep at night as originally planned.

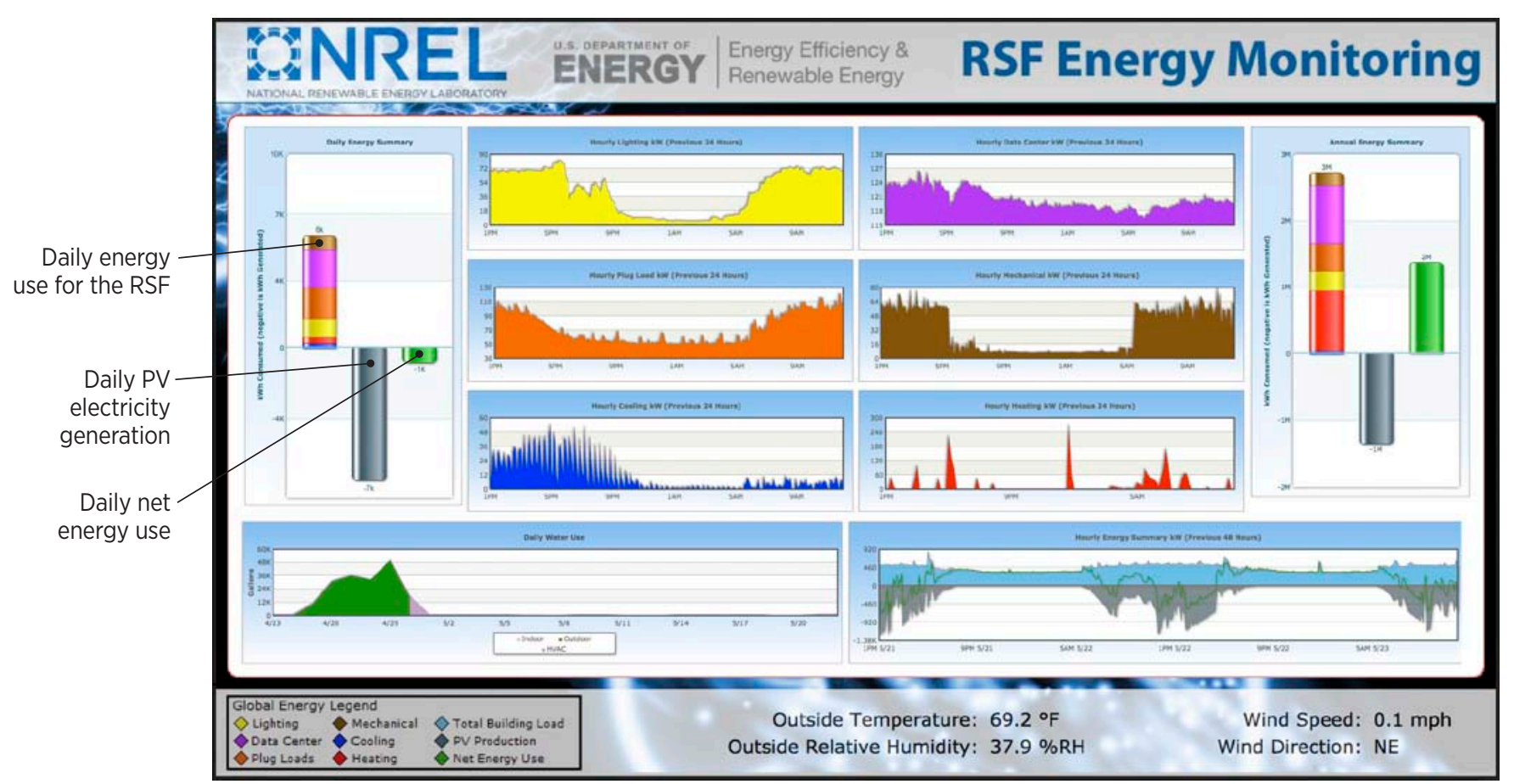

The RSF is a living laboratory-energy usage is continuously monitored. This energy monitoring display is located in the RSF Lobby so employees and visitors can see how the building is performing real-time. The far left bar chart shows daily energy use, daily energy produced by onsite photovoltaics, and the net energy. 
Each employee has a desktop-based power strip to plug in their laptop, monitor, task light, and chargers, but they have not fully utilized the controls to manage which items power off when not in use. Based on these findings, NREL is considering options to develop an optimal plug load control system that would disconnect all plugs at night.

Another operations lesson is that two refrigerators per break room in each of the 14 wings of the building are sometimes excessive. Some groups in the building have unplugged their extra refrigerator.

Small fixes can sometimes make a huge difference in energy use. Even though an ENERGY STAR ${ }^{\circledR}$ ice machine was installed in the lunch room catering kitchen, simply adding a $\$ 15$ programmable outlet resulted in an extra 52\% in energy savings for that device.

A final opportunity for improvement for RSF plug loads is the need to utilize more switched outlets or controllable outlets - or allow for programmable plugs. The RSF's lobby energy monitoring displays, for example, are on all night but don't need to be.

\section{Metering}

Metering is critical to show how buildings systems are operating and how much - or how little - energy is being used. In the RSF, one of the requirements in the original RFP was to provide an energy use display. These displays clearly show the electrical distribution within the building and are useful for the building's operations staff and the buildings occupants to see how the building is performing. After the building was complete, a separate meter was added to measure the data center's chilled water.

\section{Daylighting and Glare Solutions}

Daylighting is one of the most important features of the RSF design. All of the RSF's workstations are daylit, and no employee is more than 30 feet from a window. With the building now open, the overhead lights are fully dimmed ( $10 \%$ power) or completely off when it is sunny. Cleaning crews are asked to work during daylight hours to further reduce the need for overhead lighting.

\section{FIGURE 7 RSF Weekday Plug Load Power Density}

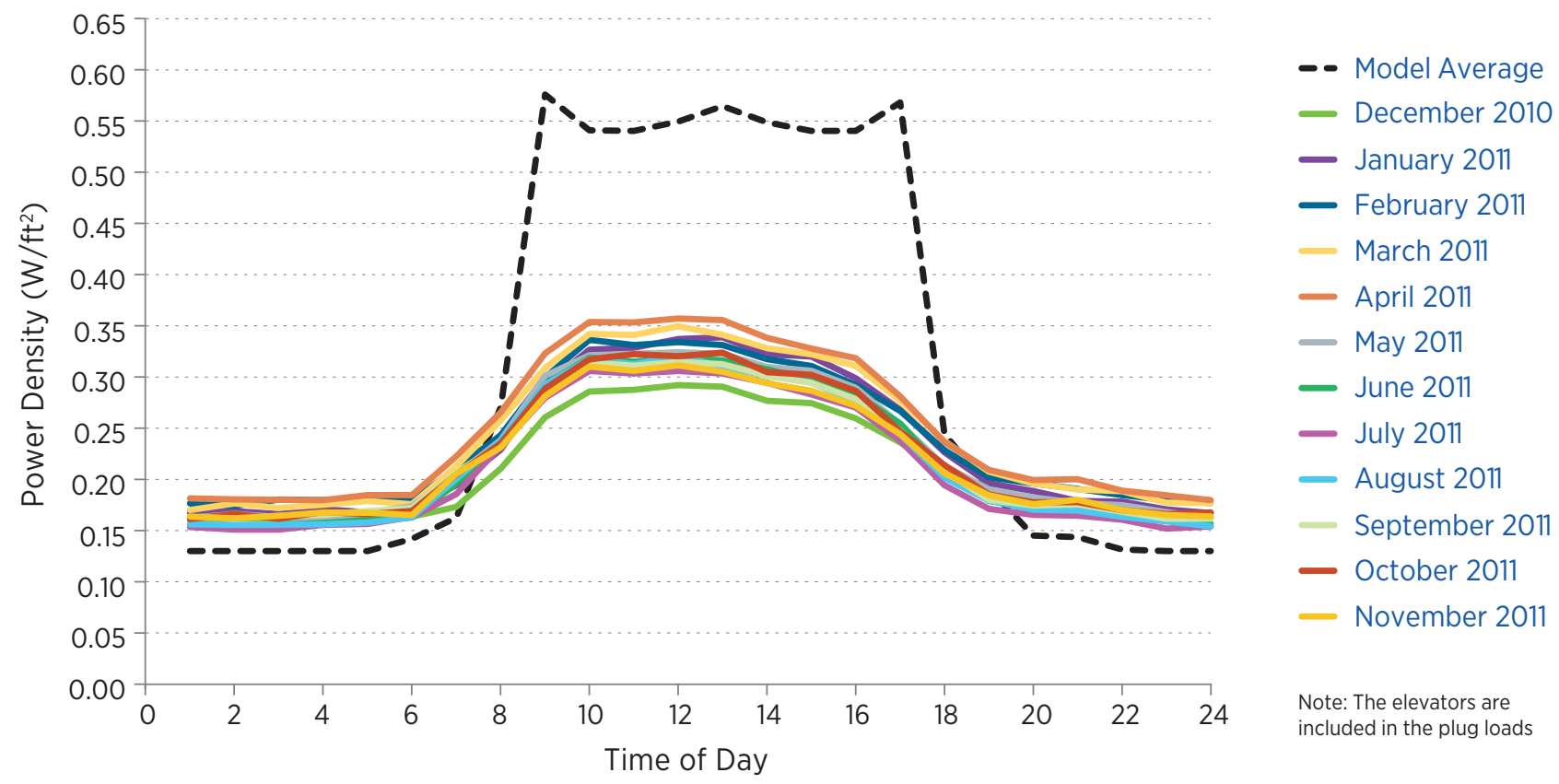

The RSF weekday plug load data shows that employees are away from their desks more frequently than the energy model predicted, resulting in reduced plug loads. Employees may be attending meetings in huddle and conference rooms, telecommuting, or on travel. Figure by Stacy Buchanan, NREL 
Even in a building designed to eliminate direct glare from the sun, the RSF (and other fully daylit buildings) still have issues with "indirect" glare, including bright spots on ceiling and light fixtures and bright backgrounds.

RSF occupants are encouraged to try different options to mitigate the glare, such as adjusting their monitor brightness and tilt, adjusting their workstation, using diffusing films in the windows, adding plants to diffuse light, or even adding optional privacy screens to their workstation walls. The privacy screens are a last resort as they also block the views for other staff.

One known glare concern is that direct sun enters the workspaces under the window louvers on the upper part of the window. This issue is now being addressed by the project team to develop a way to cover the gap.

\section{Lighting Controls}

There have been several lessons learned for lighting controls in the RSF. Vacancy sensors that were installed in private offices (daylit) are successful, and night sweeps are turning off almost all lights. Only two to three $\mathrm{kW}$ of lights remain on night, with about $700 \mathrm{~W}$ used for controls. Some employees have requested two task lights to help light work surfaces when needed.

Engineers have determined that all lights should be controlled based on daylighting, including egress lights and stairwells.

\section{HVAC}

Forty-two miles of piping deliver radiant heating and cooling to the RSF, and building operations data show that this is working well. Humidity is often a concern when radiant cooling is used; however, for this building, occupant comfort has turned out to be the more critical issue.

During the summer, even though the humidity levels met comfort conditions set forth in ASHRAE (American Society of Heating, Refrigerating, and Air-Conditioning Engineers) Standard 55 - Thermal Environmental Conditions for Human Occupancy, Colorado occupants are accustomed to dry climates. The increase in humidity levels from the evaporative cooling created discomfort for some employees. As a result, maintenance staff adjusted the amount of evaporative cooling.
The RSF's operable windows and night flushing has proven to be a useful way to remove unwanted humidity from the building.

\section{Outdoor Air Heating}

Waste heat from the RSF's data center, combined with heat from the thermal mass in the basement labyrinth, provides most of the heating required above $35^{\circ} \mathrm{F}$. The building's transpired solar collector on the southern side of the south wing can provide more heating when the thermal mass and data center heat are insufficient. This preheats air that is channeled through floor ducts and is exhausted through the center core.

\section{Window Frames}

The RSF's thermally broken window frames are the weak point in the thermal envelope of the building. While triple pane operable windows are optimal, better frames are needed to achieve optimal energy efficiency. In fact, the thermal performance is much lower than assumed in calculations for most of the project. Getting performance calculated for specific window configuration is critical, and this information should be gathered as early as possible.

\section{Data Center Energy Use Lower than Expected}

The data center is currently using 38 watts per person for 2300 NREL staff, which is dramatically lower than the model predicted - 65 watts per person with a total of only 1200 staff.

The data center minimizes energy use by adopting the newest data center cooling temperature guidelines and taking full advantage of hot isle containment. These strategies reduce the energy load sufficiently that the data center can be cooled by efficient evaporative cooling and single-pass outdoor air $99 \%$ of the year.

Fully containing the hot aisle has proved to be a challenge, and a few "hot spots" were found to be driving up the PUE. NREL is starting to control the hot aisle based on a return temperature of about 80 degrees. 


\section{Managing and Operating the RSF}

Because NREL employees who would be managing and operating the RSF were included in the project team early on, both the building manager and lead maintenance technician had complete knowledge and training regarding the significant building systems. The transition from construction to building operations was smooth.

\section{Building Occupants are Key to Success}

Engaging employees who are moving into a new, highly energy efficient building is critical to its successful operation. The decision to build and operate the RSF as a very low energy use building meant that NREL's management and staff working in the building had to understand and share the same value of energy efficiency.

Energy savings at the RSF have resulted from the many changes in the workplace culture and employee behavior:

- Tall interior office partitions that impact daylighting were not allowed, regardless of level of employee.

- The building "sleeps" at night with nearly all equipment and lights off, thanks to effective lighting controls, programmable power strips, and other building controls.

- Employees are expected to open or close their windows at the correct times.

- Employees use laptop computers instead of tower computers

- Prior to move-in, NREL's information technology staff and commercial buildings researchers established guidelines for the number and type of multi-function copy/fax/scanners, refrigerators, coffee pots, and task lights at work stations.

- After move-in, building engineers established guidelines for the type of plug-in equipment allowed in the building, and employees are learning that "every watt counts." For example, when one organization requested a new break room tea kettle to boil water (as opposed to microwaving), the potential energy use for the kettle was examined and found to be an acceptable additional plug load.

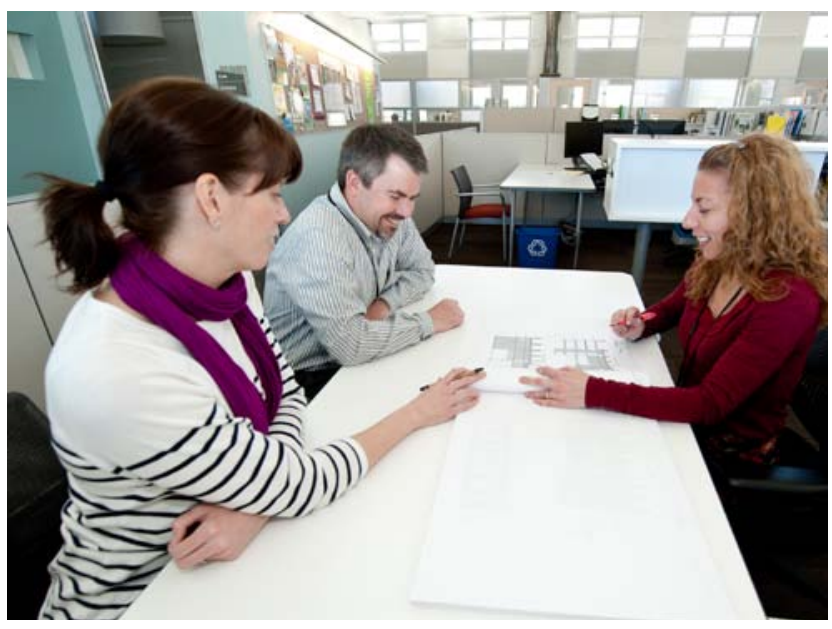

Even with high-performance, innovative building features, NREL has found that $30 \%$ of building performance is related to occupant behavior. Photo by Dennis Schroeder, NREL/PIX 18637 


\section{Top "Must Haves" for a Successful Design-Build Project}

Here are the top "must haves" for a successful DB project:

- Need owner's proactive safety culture and commitment to safe building design, construction, and operation

- Need owner's extensive up-front planning to determine building requirements

- Need owner's commitment and training to using performance-based DB

- Use DBIA’s best practices

- Obtain competitive pricing by providing a multitiered project objectives checklist in RFP

- Fund stipend pool to offset offer or proposal costs

- Obtain complete and accurate proposals by holding one-on-one meetings with offerers and allow offerers to review and comment on draft RFP

- Implement an award fee incentive program for winning DB team

- Develop challenging but achievable performance goals and substantiation criteria

- Require substantiation to make sure that project goals are on track at specific points in the process

- Commit to energy model as the primary driver for design decisions

- Build trust between owner and DB team, beginning with a non-adversarial acquisition process

- Collaborate throughout the project

- Engage future occupants of the building by educating about building design, features, and occupants' role in helping building perform.

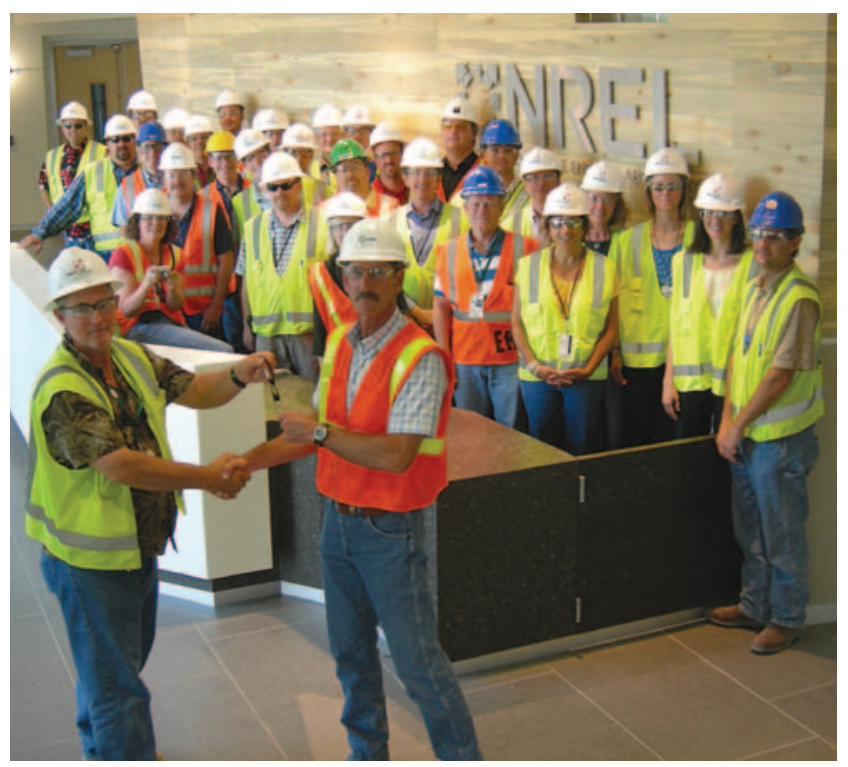

Haselden Construction hands over the RSF keys at substantial completion on June 10, 2010. Photo by Nicki Johnson, NREL/PIX 19444 


\section{Top 10 Tips for Design-Build Projects}

Here are the top 10 tips that DOE/NREL has implemented in subsequent DB projects:

1 Identify requirements for security systems early in the planning process

2 Define and agree on programming requirements prior to developing the RFP

3 Clearly define project during RFP preparation; include as many known details as possible

4 Ensure building energy efficiency experts are working on project

5 Enhance DB team's familiarity with DOE regulations

6 Require a more structured design review process for construction line item projects

7 Enhance owner's commitment to thoroughly review design documents to avoid surprises during construction

8 Continually update the energy model throughout the $\mathrm{DB}$ and measurement process

9 Integrate energy into the discussion of tradeoffs during decision making

10 Clarify roles of construction commissioning vs. third party commissioning. 


\section{Appendix A: List of Acronyms}

3PQ Preferred Price Priority Queue

CD Critical Decision

DAB Design Advisory Board

DB Design-build

DBIA Design Build Institute of America

DOAS Dedicated outdoor air system

DOE U.S. Department of Energy

DOE-GO U.S. Department of Energy Golden Field Office

EERE Office of Energy Efficiency and Renewable Energy

EUI Energy use intensity

FAR Federal Acquisition Regulations

HAA Hazard Activity Analysis

IPT Integrated Project Team

LEED ${ }^{\circledR} \quad$ Leadership in Energy and Environmental Design

NREL National Renewable Energy Laboratory

PPA Power purchase agreement

PV Photovoltaics

RFP Request for Proposals

RFQ Request for Qualifications

REC Renewable Energy Credits

RSF Research Support Facility

SET Source Evaluation Team

STM South Table Mountain site

TTF Thermal Test Facility

UFAD Under-floor air distribution 


\section{For More Information}

There are numerous resources available online for more information about the RSF and the PerformanceBased Design-Build process. Visit the RSF Website at www.nrel.gov/rsf for access to the Request for Proposal documents and various publications, videos, and presentations.

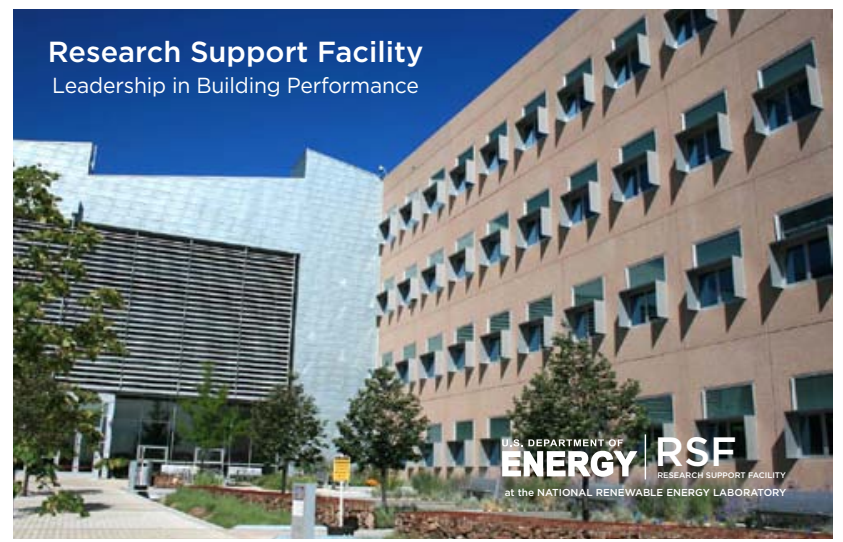

The Leadership in Building Performance brochure provides an overview of the building, high performance features, green data center, and the workplace of the future.

\section{YouTube Videos}

- RSF Documentary

- Data Center Tour

- Beetle Kill Wall

- Electrochromic Window Research

- Time-lapse of RSF Construction

\section{Presentations}

- The Road to Net Zero

- Energy Goals and Design Features

- Performance-based Design-Build Process

- Cost Considerations

- Preparing For and Changing Occupant Behaviors

\section{Technical Publications}

- Reducing Data Center Loads for a Large-Scale, Low Energy Office Building

- Using an Energy Performance-Based DesignBuild Process to Procure a Large Scale LowEnergy Building

- Reducing Plug and Process Loads for a Large Scale, Low Energy Office Building: NREL's Research Support Facility

- Role of Modeling When Designing for Absolute Energy Use Intensity Requirements in a DesignBuild Framework

- Energy Use Intensity and Its Influence on the Integrated Daylighting Design of a Large Net-Zero Energy Building

- On the Use of Integrated Daylighting and Energy Simulations to Drive the Design of a Large Net-Zero Energy Office Building

- Main Street Net-Zero Energy Buildings: The Net Zero Energy Method in Concept and Practice

- Automated Multivariate Optimization Tool for Energy Analysis

- A Handbook for Planning and Conducting Charrettes for High-Performance Projects, 2nd edition

- Net-Zero Energy Buildings: A Classification System Based on Renewable Energy Supply Options

- Zero Energy Buildings: A Critical Look at the Definition 
"We want to take energy efficiency to Main Street.

The key is to make it a requirement and integrate energy efficiency early in the design process."

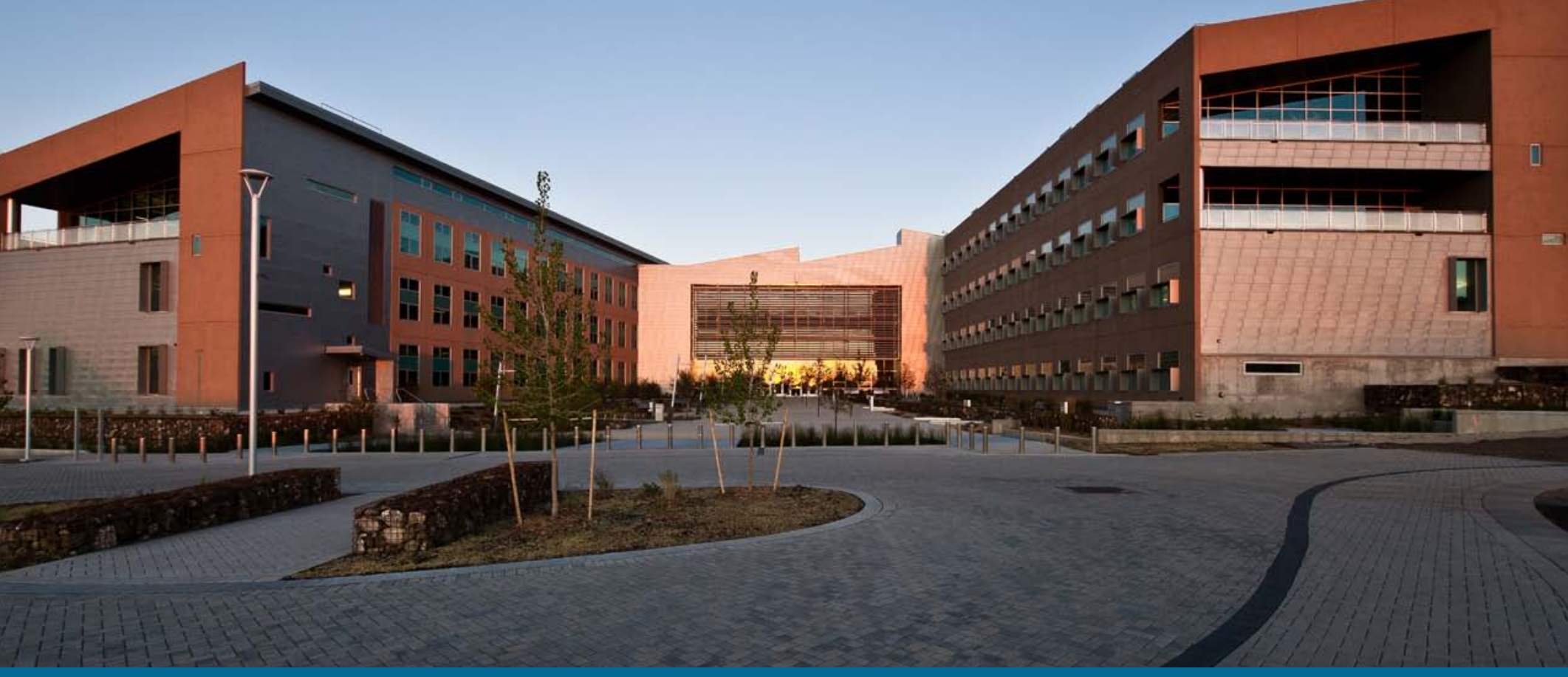

\section{Energy Efficiency \&} Renewable Energy
For more information, visit: eere.energy.gov

Printed with a renewable-source ink on paper containing at least $50 \%$ wastepaper, including $10 \%$ post consumer waste.
Cover photo by Dennis Schroeder, NREL/PIX 17831; Illustration from RNL. Back photo by Dennis Schroeder, NREL/PIX 17820

DOE/GO-102012-3293 • June 2012

LEED and the related logo is a trademark owned by the U.S. Green Building Council and is used with permission. 